\title{
IL SENSO DELLA CROCE FORME LITURGICHE ED ESPRESSIONI ARTISTICHE IN SANTA GIULIA DI BRESCIA
}

FRANCESCA STROPPA

UDC: $27-788(450.256)$ 27-526

Original scientific paper

Manuscript received: 14. 02. 2017.

Revised manuscript accepted: 17. 02. 2017. DOI: 10.1484/J.HAM.5.113711
F. Stroppa Dipartimento di storia moderna e contemporanea Università Cattolica del Sacro Cuore Largo A. Gemelli, 1 20123 Milano, Italia francesca.stroppa@unicatt.it; stroppa.francesca@gmail.com

The essay analyzes the image of Giulia, the carthaginian martyr - crucified for not having renounced of her faith - along with the large and well-known cross of Desiderio, in the liturgical and devotional practices of the monastery of San Salvatore - Santa Giulia in Brescia. The precious relics, preserved in the crypt of the monastery founded by the Lombard king, Desiderio, and his wife, Ansa, and in particular the relics of Saint Julia become, before the beginning of the eleventh century, the ideological horizon for self-representation of the nuns that, around the cross, build their path of monastic asceticism where the cross of Desiderio becomes the natural corollary in connection with the passion of Christ in a very original, clever and erudite mix of art and faith.

Keywords: Cross, the monastery of San Salvatore, Saint Julia of Carthage, Brescia (Italy), Cross of Desiderio, Treasure of the Holy Crosses, Cathedral, reliquary cross, Costantino, Elena

Nelle fonti liturgiche, nei lacerti delle strutture e nelle decorazioni dell'antico monastero di San Salvatore-Santa Giulia di Brescia ${ }^{1}$ si rintraccia un uso della croce particolarmente significativo - seppur ora celato a causa dei pesanti cambiamenti d'uso, dei restauri e dei rifacimenti architettonici $^{2}$ - che può essere meglio compreso solo se inserito nel più ampio contesto che lega il cenobio all'ambiente cittadino $\mathrm{e}$, in generale, all'ecumene cristiana.
Durante le ultime indagini ${ }^{3}$ sono emersi nuovi elementi che mostrano una elaborata costruzione teologica, impostata sul culto della croce, che si sviluppa intorno alla fondazione del cenobio, alla sua intitolazione, alle reliquie e alle strutture monastiche. Gli approfondimenti sulla storia della santa dedicataria, Giulia ${ }^{4}$, la scelta dei martiri sepolti al suo fianco (Elpis, Pistis, Agape, Ippolito, Pimeneo, Giustino e i martiri innocenti), i fondatori del cenobio (Ansa e Deside-

${ }^{1}$ Per la storia del cenobio si vedano gli interventi di Gabriele Archetti [ID., Per la storia di Santa Giulia nel medioevo: note storiche in margine ad alcune pubblicazioni recenti, in Brixia sacra. Memorie storiche della diocesi di Brescia, ser. $3^{\mathrm{a}}$, V, 1-2 (2000), p. 5-44; ID., Vita e ambienti del monastero dopo il Mille, in R. Stradiotti (a cura di), San Salvatore - Santa Giulia a Brescia. Il monastero nella storia, Milano, 2001, p. 109-132; ID., Pellegrini e ospitalità nel medioevo. Dalla storiografia locale all'ospedale di Santa Giulia di Brescia, in G. Archetti (a cura di), Lungo le strade della fede. Pellegrini e pellegrinaggio nel Bresciano, Atti della giornata di studio (Brescia, 16 dicembre 2000), Brescia, 2001 (Brixia sacra. Memorie storiche della diocesi di Brescia, VI, 3-4), p. 69-128] nelle cui ricerche per la prima volta si indicano gli spazi del monastero, successivamente utilizzati nei lavori di ricostruzione da Andrea Breda [ID., Strutture architettoniche e fonti scritte, in R. Stradiotti (a cura di), San Salvatore - Santa Giulia a Brescia, op. cit. (n. 1), p. 133-149] e disegnati da Lorenzo Confortini mediati da indicazioni di scavo di Gian Pietro Brogiolo [ID., Gli edifici monastici nelle fasi altomedievali, in R. Stradiotti (a cura di), San Salvatore - Santa Giulia a Brescia, op. cit. (n. 1), p. 61-70], da Gianpietro Belotti [ID., Il monastero dalla riforma cassinese al XVI secolo, in R. Stradiotti (a cura di), San Salvatore - Santa Giulia a Brescia, op. cit. (n. 1), p. 169-192; ID., Le vicende del monastero dal XVII secolo alla soppressione napoleonica, Ibidem, p. 307-311] e da Monica Ibsen [M. IBSEN, "Magno et optimo tesauro". Intorno a reliquie e altari in San Salvatore di Brescia, in G. Archetti (a cura di), "Inquirere veritatem". Studi in memoria di mons. Antonio Masetti Zannini, Brescia, 2007 (Brixia sacra. Memorie storiche della diocesi di Brescia, XII, 1), p. 219-242]; per la parte moderna si veda anche Giovanni Spinelli [ID., L'applicazione della riforma di Santa Giustina al monastero di Santa Giulia nel XV secolo, in R. Stradiotti (a cura di), San Salvatore - Santa Giulia a Brescia, op. cit. (n. 1), p. 193-199; ID., La storiografia sul monumento nell'età moderna e contemporanea, in C. Stella, G. Brentegani (a cura di), S. Giulia di Brescia. Archeologia, arte, storia di un monastero regio dai longobardi al Barbarossa, Atti del convegno (Brescia, 4-5 maggio 1990), Brescia, 1992, p. 21-28]. Sulla gestione patrimoniale si vedano, almeno, F. Menant, Le monastère de S. Giulia et le monde féodal. Premiers éléments d'information et perspectives de recherche, in S. Giulia di Brescia. Archeologia, arte, storia, op. cit. (n. 1), p. 119-130; G. PASQUALI, Gestione economica e controllo sociale di San Salvatore-Santa Giulia dall'epoca longobarda all'età comunale, Ibidem, p. 131-146; e, per uno sguardo complessivo, G. ARCHETTI, Il monachesimo bresciano nella storiografia di fine secolo, in G. Andenna (a cura di), Dove va la storiografia monastica in Europa? Temi e metodi di ricerca per lo studio della vita monastica e regolare in età medievale alle soglie del terzo millennio, Atti del convegno internazionale (Brescia-Rodengo, 23-25 marzo 2000), Milano, 2001, p. 451-471; inoltre G. Archetti (a cura di), Le carte della "curtis" di Migliarina, trascrizione di B. Carboni, revisione critica e indici di M.C. Succurro, in corso di stampa, come pure il contributo di G. ARCHETTI, "Secundum monasticam disciplinam". San Salvatore di Brescia e le trasformazioni istituzionali di un monastero regio, in G. Archetti (a cura di), Desiderio. Il progetto politico dell'ultimo re longobardo, Atti del Primo convegno internazionale del Centro studi longobardi (Brescia, 21-24 marzo 2013), Spoleto, 2015 (Centro studi longobardi. Convegni, 1), p. 631-68o.

${ }^{2}$ Sulla questione si veda G. ARCHETTI, “Secundum monasticam disciplinam”, op. cit. (n. 1); F. STROPPA, La basilica di San Salvatore: i cicli pittorici altomedievali. Per una rilettura del complesso monastico di Santa Giulia di Brescia, in G. Archetti (a cura di), Desiderio. La basilica di San Salvatore, Atti del Primo convengo internazionale del Centro studi Longobardi (Brescia, 21-24 marzo 2013), Spoleto, 2016 (Centro studi longobardi. Convegni 1.2), con bibliografia precedente; M. DE PAOLI, Strutture architettoniche e restauri in Santa Giulia di Brescia: la cripta di San Salvatore, in questo volume.

${ }^{3}$ Cfr. F. STROPPA, Santa Giulia di Brescia. Un percorso sull'iconografia claustrale della martire cartaginese, in Brixia Sacra. Memorie storiche della diocesi di Brescia, ser. $3^{\mathrm{a}}$, XVI, 1-2 (2011), p. 61-172; EAD., Santa Giulia. Percorsi artistici nell'agiografia monastica: l'esempio di San Salvatore di Brescia, Roma, 2012; EAD., L'immagine della martire Giulia nel complesso monastico di San Salvatore di Brescia: mobilità di maestranze, di materiali e di idee, in M. Jurkovic, X. Barral i Altet (eds.), Mobility of artists, transfer of forms, functions, works of art and ideas in medieval mediterranean Europe: the role of the ports, Atti del XXII convegno internazionale di studi IRCLAMA (Poreč, 21-24 maggio 2015), Zagreb-Motovum, 2016 (Hortus artium medievalium, 22), p. 265-281; EAD., 


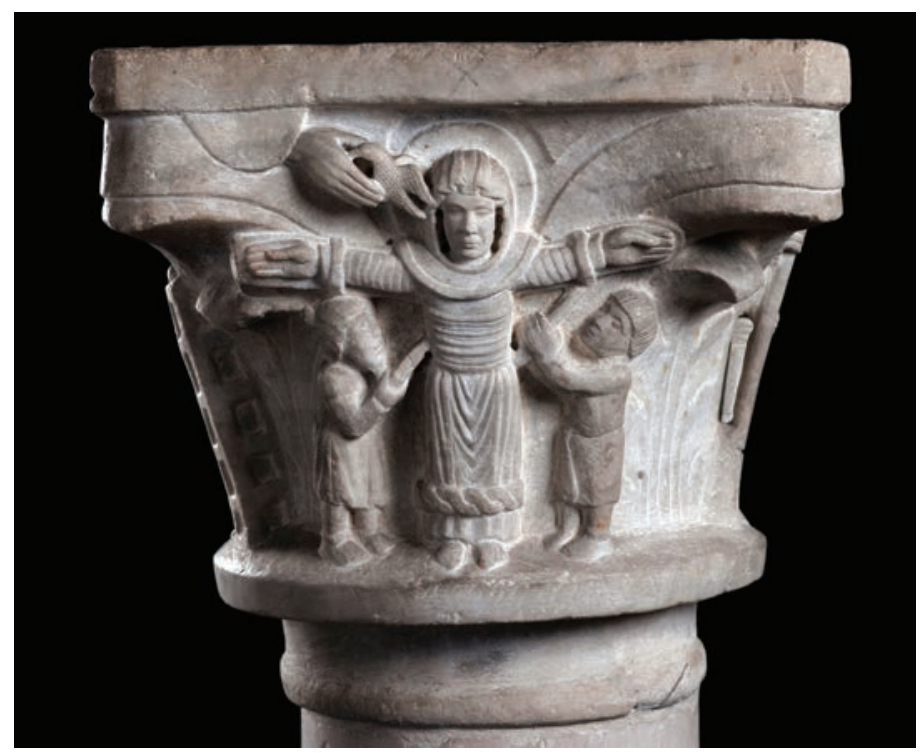

Fig. 1. Brescia, Musei Civici, capitello proveniente dalla cripta, martirio di santa Giulia (foto Studio Rapuzzi).

rio), le intelaiature strutturali e in particolare le cappelle e gli altari, presenti nel monastero, hanno suggerito che nel corso del X secolo, all'interno della comunità femminile, venne elaborata una nuova immagine religiosa, incentrata sul culto della croce, adatta a commemorare le origini della fondazione claustrale attingendo a modelli della tradizione occidentale e orientale, volti a celebrare il Salvatore e i santi martiri conservati al suo interno, glorificando così anche i patroni che con la loro protezione - a cominciare dalla famiglia imperiale - davano lustro all'abbazia.

Per realizzare questa complessa costruzione ideologi$\mathrm{ca}^{5}$ - fondata su calchi letterari di fonti classiche, storiche, agiografiche e delle sacre scritture - si pose l'attenzione sulla croce che, divenuta simbolo della vittoria cristiana sulla morte, costituisce il perno intorno a cui si incontrano le nature umana e divina del Cristo. Il tema dell'incarnazione

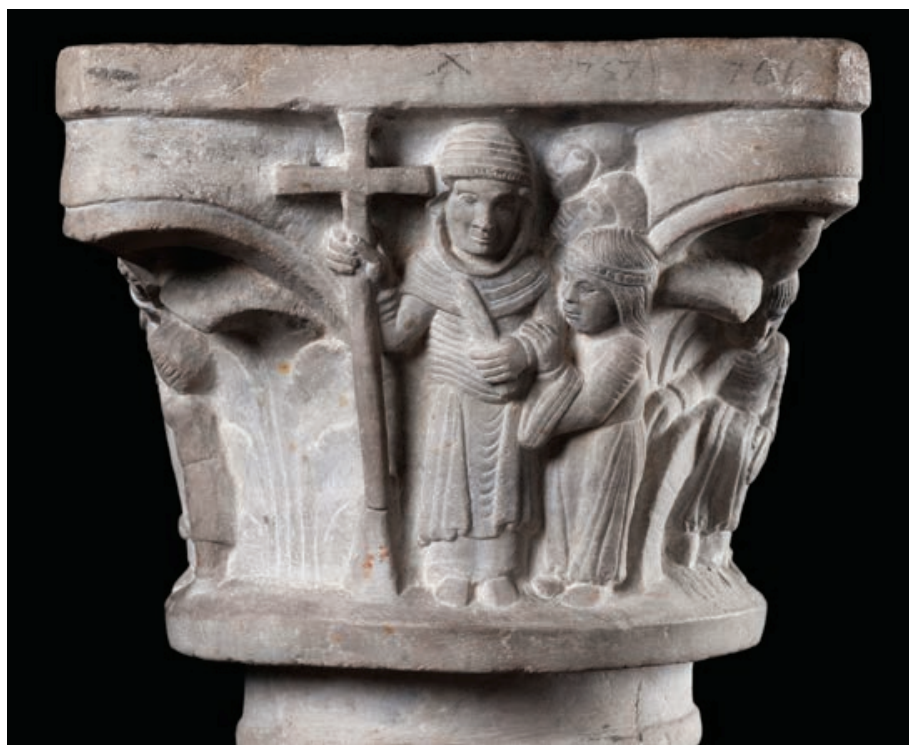

Fig. 2. Brescia, Musei Civici, capitello proveniente dalla cripta, santa Giulia con Fede, Speranza e Carità (foto Studio Rapuzzi).

e della salvezza - oggetto di fraintendimenti nel corso dei secoli e di posizioni eterodosse - è fondamentale nell'antropologia cristiana dove la croce, da strumento di morte, diviene simbolo di vita e di vittoria, elemento distintivo del sovrano vincitore: Vexilla regis prodeunt, come recita l'incipit dell'inno di Venanzio Fortunato ${ }^{6}$. Rappresenta pertanto il potere temporale e dell'Impero che, come per Costantino, con quel segno celebra il trionfo del Cristo acquisito attraverso la passione, la morte in croce e la risurrezione.

\section{SANTA DEDICATARIA E MARTIRI}

L’intitolazione del cenobio bresciano è al Salvatore e solo a partire dal 915 è attestata per la prima volta anche la figura della martire Giulia7, la santa cartaginese, crocifissa come il Cristo (fig. 1) e raffigurata nel monastero bresciano,

La basilica di San Salvatore: i cicli pittorici altomedievali, op. cit. (n. 2); EAD., L'immagine di santa Giulia nell'autocoscienza monastica di San Salvatore di Brescia, in C. Ebanista, M. Rotili (a cura di), Fondazioni e rituali funerari delle aristocrazie germaniche nel contesto mediterraneo, Atti del convegno internazionale di studi (Cimitile-Santa Maria Capua Vetere, 18-19 giugno 2015), Napoli, in corso di stampa.

${ }^{4}$ Le reliquie vengono indicate nel Rituale di Santa Giulia o Ordinarium seu chronica officiorum totius anni che è conservato presso la Biblioteca Queriniana di Brescia, ms. H.VI.11 (= Rituale) ed è stato redatto sulla base di un precedente esemplare della fine del XII secolo, cfr. O. VALETTI, Scheda IV 2 , in San Salvatore di Brescia. Materiali per un museo. I, Catalogo della mostra (Brescia, giugno-novembre 1978), Brescia 1978, p. 82-83; G. ARCHETTI, Per la storia di Santa Giulia, op. cit. (n. 1), p. 14, 22-28; S. GAVINELLI, La liturgia del cenobio di Santa Giulia in età comunale e signorile attraverso il "Liber ordinarius", in G. Andenna (a cura di), Culto e storia in Santa Giulia, Atti del convegno (Brescia, 20 ottobre 2000), Brescia, 2001, p. 121-148. Per la tradizione agiografica e liturgica relativa al monastero cfr. G. ARCHETTI, Per la storia di Santa Giulia, op. cit. (n. 1), p. 5-44; ID., Vita e ambienti del monastero, op. cit. (n. 1), p. 109-132; G. SILAGI, I testi liturgici per la Santa, in Culto e storia in Santa Giulia, op. cit. (n. 4), p. 15-28; M. IBSEN, "Magno et optimo tesauro", op. cit. (n. 1), p. 219-242. Per la martire cartaginese cfr. E. CAMISANI, s.v., Giulia, in Bibliotheca sanctorum, VI, Roma, 1965, col. 1164-1168; inoltre, G. BERGAMASCHI, Una redazione 'bresciana' della "Passio sanctae Iuliae" in Toscana, in Nuova rivista storica, LXXXVII, 3 (2003), p. 625-668; ID., Santa Giulia a Lucca: la chiesa e il culto della santa, in Nuova rivista storica, LX (2006), p. 763-782; ID., Il carme "Ergo, pii fratres" e gli inni per santa Giulia, in M.T. Rosa Barezzani, R. Tibaldi (a cura di), Musica e liturgie nel medioevo bresciano (secoli XI-XV), Atti dell'incontro nazionale di studio (Brescia, 3-4 aprile 2008), Brescia, 2009 (Storia, cultura e società, 2), p. 191-247; ID., Da Cartagine alla Toscana a Brescia: i percorsi del culto di Santa Giulia, in R. Stopani, F. Vanni (a cura di), La via francigena in Valdelsa: storia, percorsi e cultura di una strada medievale, Atti del convegno (Colle Val d'Elsa, Sant'Appiano, Certaldo, 23-25 ottobre 2009), Firenze, 2009, p. 211-252; ID., "La vita di santa Giulia" di Ottavio Rossi (1605), in Annali queriniani, X (2009), p. 7-62; ID., I capelli di santa Giulia, in G. Archetti, G. Donni (a cura di) La memoria della fede. Studi storici offerti a S.S. Benedetto XVI nel centenario della rivista "Brixia sacra", Brescia, 2009 (Brixia sacra. Memorie storiche della diocesi di Brescia, XIV, 1), p. 311-321; M. BETTELLI, G. BERGAMASCHI, "Felix Gorgona... felicior tamen Brixia": la traslazione di santa Giulia, in C. Alzati, G. Rossetti (a cura di), Profili istituzionali della santità medioevale. Culti importati, culti esportati e culti autoctoni nella Toscana Occidentale e nella circolazione mediterranea ed europea, Pisa, 2010 (Piccola Biblioteca GISEM, 24), p. 143-204; R. TIBALDI, L’ufficio liturgico di santa Giulia (Graduale-Breviario, cod. Oxford, Bodl. Libr., Canon. Lit. 366, sec. XI), in M.T. Rosa Barezzani, R. Tibaldi (a cura di), Musica e liturgie, op. cit. (n. 4), p. 133-189. Sul patrimonio reliquiario, oltre ai testi citati, cfr. P. TOMEA, Intorno a Santa Giulia. Le traslazioni e le "rapine" dei corpi santi nel regno longobardo (Neustria e Austria), in G. Andenna (a cura di), Culto e storia in Santa Giulia, op. cit. (n. 4), p. 29-102 e F. STROPPA, Santa Giulia di Brescia, op. cit. (n. 3), p. 61-172; EAD., Santa Giulia. Percorsi artistici, op. cit. (n. 3); EAD., L'immagine di santa Giulia nell'autocoscienza monastica, op. cit. (n. 3); le reliquie riposano ancora a Brescia, v. EAD., Santa Giulia. Percorsi artistici, op. cit. (n. 3), p. 22-25; sull'arrivo delle reliquie EAD., L’immagine della martire Giulia nel complesso monastico, op. cit. (n. 3), p. $265-281$.

${ }^{5}$ F. STROPPA, L'immagine della martire Giulia nel complesso monastico, op. cit. (n. 3).

${ }^{6}$ VENANCE FORTUNAT, Poèmes, Livres I-IV, éd. par M. Reydellet, Paris, 1994, lib. II, 6, Hymnus in honore sanctae crucis, p. 57-58.

${ }_{7}$ G. ARCHETTI, "Secundum monasticam disciplinam”, op. cit. (n. 1), p. 66o-668. 
fin dai tempi più antichi, come una fanciulla accompagnata da tre figure femminili Elpis, Pistis e Agape, allegorie delle tre virtù teologali (fig. 2), insieme alla loro madre Sophia, immagine della sapienza divina. La soluzione iconografica, che richiama l'elemento trinitario, rimane costante e inalterata dal medioevo alla fine del Settecento ${ }^{8}$, connotandosi come la presenza ineffabile del divino, visibile attraverso le tre bambine, poste a sostegno del trapasso di Giulia nella suprema prova del martirio.

La necessità di un accompagnamento delle virtù teologali diventa pertanto il modo per identificare la vergine cartaginese con la croce stessa, quale modello di Cristo mimesi e strumento di emulazione per la comunità femminile che si riconosceva in figure, simboli e esperienze spirituali vissute nella clausura. Le benedettine vedono nell'esempio di Giulia, dei martiri, dei santi e degli eremiti raffigurati nel cenobio ${ }^{9}$, un modello di riferimento e la riflessione cristiana dava al monachesimo il compito di trasmettere nel tempo, sia pure secondo una nuova veste, la spiritualità eroica dei martiri dell'antichità, giacché il monaco come atleta e soldato di Cristo offriva la sua vita a Dio quale olocausto vivente, alla stregua dei martiri, nella preghiera continua ${ }^{10}$. Già alla fine IV secolo, nella gesta di Martino di Tours, Sulpicio Severo parla della vita del santo monaco come di un martirio sine cruore non meno meritevole di quello dei campioni della fede durante le persecuzioni" ${ }^{1}$.
La raffinata allegoria, ideata per il cenobio giuliano, sceglie una giovane donna che non solo subisce il martirio del Cristo, ma che richiama nel nome le gesta gloriose della gens Iulia e le origini cartaginesi, alla stregua di Didone fondatrice di una nuova città ed esemplare nell'opporsi al nemico sino alla fine dei suoi giorni ${ }^{12}$. Il rimando mitico alle origini imperiali viene rafforzato, nell'ordinario liturgico ${ }^{13}$, dalla coincidenza dell'erezione del cenobio, nel 753, con l'anno di fondazione di Roma avvenuto, in modo speculare, dopo la venuta del Cristo. Inoltre, spie di un racconto mitizzato, costruito su una tradizione antica ma viva, permangono nell'uso della figura imperiale di Augusto nel cenobio fino in età moderna, come testimonia la raffigurazione nella cappella della Vergine della leggendaria visione di Ottaviano Augusto della Madonna col Bambino, al fianco della sibilla Tiburtina ${ }^{14}$. Tutto questo suggerisce l'esistenza di un'accurata programmazione che collega Giulia alla croce di Cristo, simbolo della salvezza umana, e alla regalità romana della gens Iulia.

Per rafforzare il significato connotativo dell'artificiosa cornice agiografico-letteraria, nella decorazione della navata della basilica (fig. 3), sono affrescate alcune scene della vita di Giulia, poste in parallelo con quelle di Fede, Speranza, Carità e Sapienza, e sovrastate dalle Storie del Cristo, e scolpite sequenze martiriali nel capitello della cripta posto accanto alle arche che contenevano i loro corpi ${ }^{15}$. La cronologia della

\footnotetext{
${ }_{8}^{8}$ Per un quadro storiografico generale cfr. G. PANAZZA, Ricerche in S. Salvatore di Brescia, in H. Fillitz (hrsg.), Beiträge zur Kunstgeschichte und Archäologie des Frühmittelalters, Akten zum VII. Internationalen Kongreß fur Frühmittelalterforschung (Wien, 21-28. September 1958), Graz [u.a.], 1961, p. 139-153; San Salvatore di Brescia. Materiali per un museo, I, op. cit. (n. 4); San Salvatore di Brescia. Materiali per un museo, I. Contributi per la storia del monastero e proposte per un uso culturale dell'area storica di Santa Giulia, Brescia, 1978; S. Giulia di Brescia. Archeologia, arte, storia, op. cit. (n. 1); G.P. BROGIOLO, Analisi stratigrafica del San Salvatore di Brescia. Nota preliminare, in Dai Civici Musei di arte e storia di Brescia. Studi e notizie, 3 (1987), p. 25-40; ID., Brescia altomedievale. Urbanistica ed edilizia dal IV al IX secolo, Mantova, 1993 (Documenti di archeologia, 2), p. 98-102; ID., La nuova sequenza architettonica e il problema degli affreschi del San Salvatore di Brescia, in L'arte d'Occidente. Temi e metodi. Studi in onore di A.M. Romanini, I, Roma, 1999, p. 25-34; ID., Brescia. L'eglésia de San Salvatore, in J. Camps (ed.), Catalunya a l'època carolíngia. Art i cultura abans del romànic (segles IX i X), Catalogo della mostra (16 desembre 1999-27 febrer, Museu nacional d'art de Catalunya), Barcelona, 1999, p. 161-164; C. Bertelli, G.P. Brogiolo (a cura di), Il futuro dei longobardi. L'Italia e la costruzione dell'Europa di Carlo Magno. Saggi, Milano, 200o; R. Stradiotti (a cura di), San Salvatore - Santa Giulia a Brescia, op. cit. (n. 1); G. Andenna (a cura di), Arte, cultura e religione in Santa Giulia, Brescia, 2004; G. Andenna, M. Rossi (a cura di), Società bresciana e sviluppo del romanico, Atti del convegno di studio (Brescia, 9-10 maggio 2002), Milano, 2007, passim. Inoltre si vedano per alcune precisazioni sull'aspetto pittorico di età moderna E. Lucchesi Ragni, R. Stradiotti (a cura di), Brescia nell'età della Maniera. Grandi cicli pittorici della Pinacoteca Tosio Martinengo, Catalogo della mostra (Brescia, Pinacoteca Tosio Martinengo, 10 novembre 2007-4 maggio 2008), Milano, 2007; M. Bona Castelotti, E. Lucchesi Ragni (a cura di), Pinacoteca Tosio Martinengo. Catalogo delle opere, secoli XII-XVI, con R. D’Adda, Venezia, 2014. Per gli aspetti iconografici cfr. n. 3.

9 F. STROPPA, La basilica di San Salvatore: i cicli pittorici altomedievali, op. cit. (n. 2), passim: mi riferisco alle forme eremitiche di sant'Onofrio, a quello degli oblati come sant'Obizio, alle figure femminili Cecilia, Agata, Agnese, Marta, Maria, Maddalena, Scolastica, Margherita, Barbara, Apollonia, ecc.

${ }^{10}$ Sul tema del monaco come atleta di Dio si veda: G. ARCHETTI, "Nihil operi Dei praeponatur". Il tempo dei monaci nel Medioevo, in G. Archetti, A. Baronio (a cura di), "Tempus mundi umbra aevi". Tempo e cultura del tempo tra Medioevo e età moderna, Atti dell'incontro nazionale di studio (Brescia, 29-30 marzo 2007), Brescia, 2008 (Storia, cultura e società, 1), p. 51-80; ID., "Noli pane satiari". Il pane sulla mensa dei monaci, in G. Archetti (a cura di), La civiltà del pane. Storia, tecniche e simboli dal Mediterraneo all'Atlantico, Atti del convegno internazionale di studio (Brescia, 1-6 dicembre 2014), Spoleto, 2015 (Centro studi longobardi. Ricerche, 1), p. 1663-1704; ID., "Mensura victus constituere". Il cibo dei monaci tra Oriente ed Occidente, in L'alimentazione nell'alto medioevo: pratiche, simboli, ideologie, Atti della sessantatreesima settimana di studio (Spoleto, 9-14 aprile 2015), Spoleto, 2016, p. 757-797; ID., I monaci a tavola: norme e consuetudini alimentari, in L. Pani Ermini (a cura di), "De re monastica V". Gli spazi della vita comunitaria, Atti del convegno internazionale (Roma-Subiaco, 8-10 giugno 2015), Spoleto, 2016, p. 305-327.

"SULPICIUS SEVERUS, Epistola. II, Ad Aurelium diaconum. De obitu et apparitione beati Martini, in Patrologia latina, 20, col. 180: «ha portato a compimento il martirio senza spargimento di sangue»; cfr. SULPICIO SEVERO, Lettere su Martino, introduzione, testo e traduzione e commento a cura di F. Ruggiero, Bologna, 2003.

${ }^{12}$ F. STROPPA, L'immagine della martire Giulia nel complesso monastico di San Salvatore di Brescia, op. cit. (n. 3), p. $269-271$.

${ }^{13}$ Rituale, f. 1v; cfr. S. GAVINELLI, La liturgia del cenobio di Santa Giulia, op. cit. (n. 4), p. 122-124.

${ }^{14}$ F. STROPPA, Santa Giulia di Brescia, op. cit. (n. 3), p. 134-140; EAD., Santa Giulia. Percorsi artistici, op. cit. (n. 3), p. 79-92.

${ }_{15}$ Sugli affreschi della basilica di San Salvatore e sui capitelli della cripta: G. PANAZZA, L'arte medievale nel territorio bresciano, Bergamo, 1942, p. 196-197; A. WEIS, Die langobardische Königsbasilika von Brescia: Wandlungen von Kult und Kunst nach der Rombelagerung von 756, Sigmaringen, 1977; B. BERNHARD ANDERSON, The frescoes of San Salvatore at Brescia, Ann Arbor, 1990; A. PERONI, Problemi della decorazione pittorica del S. Salvatore, in Seminario internazionale sulla decorazione pittorica del San Salvatore di Brescia, Atti del convegno (Brescia, 10-20 giugno 1981), Pavia, 1983, p. 17-46; ID., San Salvatore di Brescia: un ciclo pittorico altomedievale rivisitato, in Arte medievale, I (1983), p. 53-80; G. PANAZZA, Scheda V o8. La seconda chiesa di San Salvatore, in San Salvatore di Brescia. Materiali per un museo, I, op. cit. (n. 4), p. 102; S. LOMARTIRE, Riflessioni sulla decorazione del San Salvatore di Brescia alla luce delle nuove indagini archeologiche, in M. Exner (hrsg.), Wandmalerei des frühen Mittelalters: Bestand, Maltechnik, Konservierung, Akten Eine Tagung des Deutschen Nationalkomitees von ICOMOS (Lorsch, 10.-12. oktober 1996), München, 1998, p. 40-48; C. BERTELLI, Gli stucchi e gli affreschi, in Museo della
} 


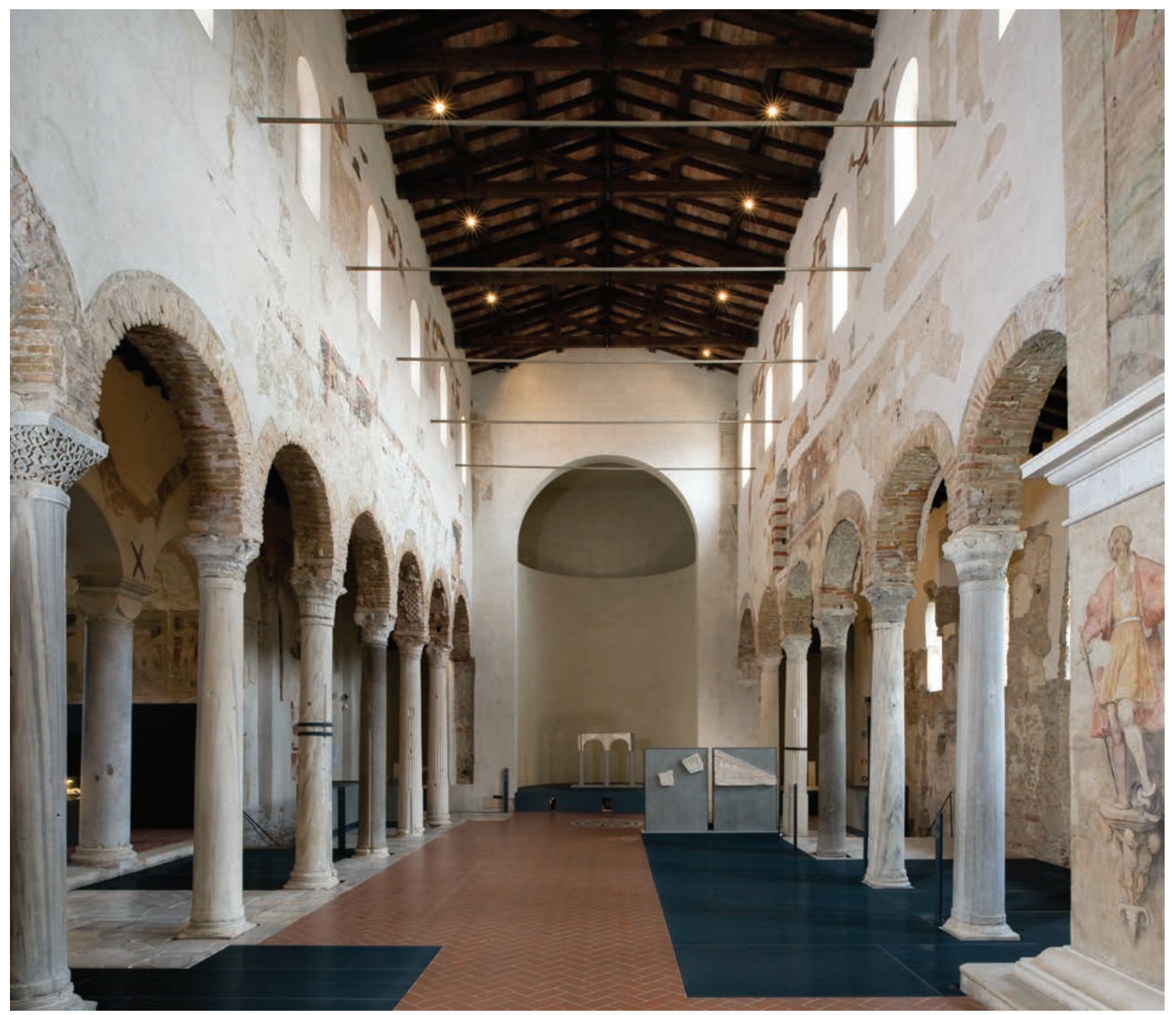

Fig. 3. Brescia, basilica di San Salvatore (foto Studio Rapuzzi).

costruzione di un tale progetto non nasce con la fondazione desideriana ma all'inizio del $\mathrm{X}$ secolo, quando al tempo di Berengario la figlia Berta, badessa del monastero, introduce la dedicazione giuliana segnando una grande novità nella liturgia claustrale ${ }^{16}$. Nell'arco di un secolo la macchina viene costruita con diversi elementi, aggiunti in corso d'opera, in parallelo alle esigenze della comunità che, nelle preghiere, nelle meditazioni, nei canti e nelle riflessioni spirituali, si immedesimava con i martiri, i confessori e in particolare con la santa eponima del monastero, divenuta simbolo di salvezza e della croce, la cui suprema testimonianza era paragonata agli ultimi giorni e alla passione di Gesù̀ ${ }^{17}$.

Individuati i soggetti iconografici relativi alle vite di Fede, Speranza e Carità, al fianco di Sofia nella parete nord della basilica (fig. 4), sebbene rimasti in modo frammentario, risulta difficile pensare alla scelta di tali temi senza la presenza di codici di trasmissione da cui attingere che giungono in Occidente solo a partire dal X secolo, come illustrato da Simona Gavinelliir e come ricordano i testi di Rosvita di Gandersheim ${ }^{19}$. Sulla base di questo elemento e

città, Brescia. L'età altomedievale. Longobardi e carolingi San Salvatore, Milano, 1999, p. 98-102; ID., Dalla regina Ansa a Ludovico II, in C. Bertelli (a cura di), Duemila anni di pittura a Brescia, I, Brescia, 2007, p. 77-85. Sugli ultimi dati di ricerca: G.P. BROGIOLO, M. IBSEN, V. GHEROLDI, Nuovi dati sulla cripta del San Salvatore di Brescia, in F. De Rubeis, F. Marazzi (a cura di), Monasteri in Europa occidentale (secoli VIII-XI): topografia e strutture, Atti del convegno internazionale (Castel San Vincenzo, 23-26 settembre 2004), Roma, 2008, p. 211-238; G.P. BROGIOLO, V. GHEROLDI, M. IBSEN, J. MITCHELL, Ulteriori ricerche sul San Salvatore II di Brescia, in Hortus artium medievalium, 16 (2010), p. 219-242; come pure V. GHEROLDI, Evidenze tecniche e rapporti stratigrafici per la cronologia del sistema decorativo della basilica di San Salvatore II, in G.P. Brogiolo (a cura di), Dalla corte regia al monastero di San Salvatore - Santa Giulia di Brescia, con F. Morandini, Mantova, 2014, p. 97-120; M. IBSEN, Sistemi decorativi per la basilica di Ansa e Desiderio, ivi, p. 141-168; J. MITCHELL, The painted decoration of San Salvatore di Brescia in context, ivi, p. 169-202; S. TONNI, I frammenti pittorici provenienti dalla chiesa di San Salvatore, ivi, p. 203-220; E. FLORIN, O. SALVADORI, Indagini di fluorescenza X portatile e stratigrafiche sulle pellicole pittoriche, ivi, p. 521-532; F. ANTONELLI, S. CANCELLIERE, L. LAZZARINI, Indagini di laboratorio con particolare riferimento agli strati preparatori del colore, ivi, p. 533-542. Cfr. n. 2, 3. ${ }^{16}$ G. ARCHETTI, "Secundum monasticam disciplinam", op. cit. (n. 1), p. 631-68o.

${ }^{17}$ F. STROPPA, Santa Giulia di Brescia, op. cit. (n. 3), p. 115-122; EAD., Santa Giulia. Percorsi artistici, op. cit. (n. 3), p. 67-74.

${ }^{18}$ S. GAVINELLI, La liturgia del cenobio di Santa Giulia, op. cit. (n. 4), p. 121-148; EAD., Testimonianze grafiche e culti santorali a Brescia, in M.T. Rosa Barezzani, R. Tibaldi (a cura di), Musica e liturgie, op. cit. (n. 4), p. 38-39; EAD., Santa Sofia e le figlie, Fede, Speranza e Carità dipinte in San Salvatore - Santa Giulia di Brescia?, in G. Archetti, G. Donni (a cura di), "Inquirere veritatem", op. cit. (n. 1), p. 83-88.

${ }^{19}$ Sul tema si veda L. ROBERTINI, Tra filologia e critica. Saggi su Panifico di Verona, Rosvita di Gandersheim e il "Liber miraculorum Sanctae Fidis", L.G.G. Ricci (a cura di), Firenze, 2004 (Opuscoli. Seconda serie, 2), in particolare il cap. Il Sapientia di Rosvita e le fonti agiografiche, p. 35-44; come pure i saggi 


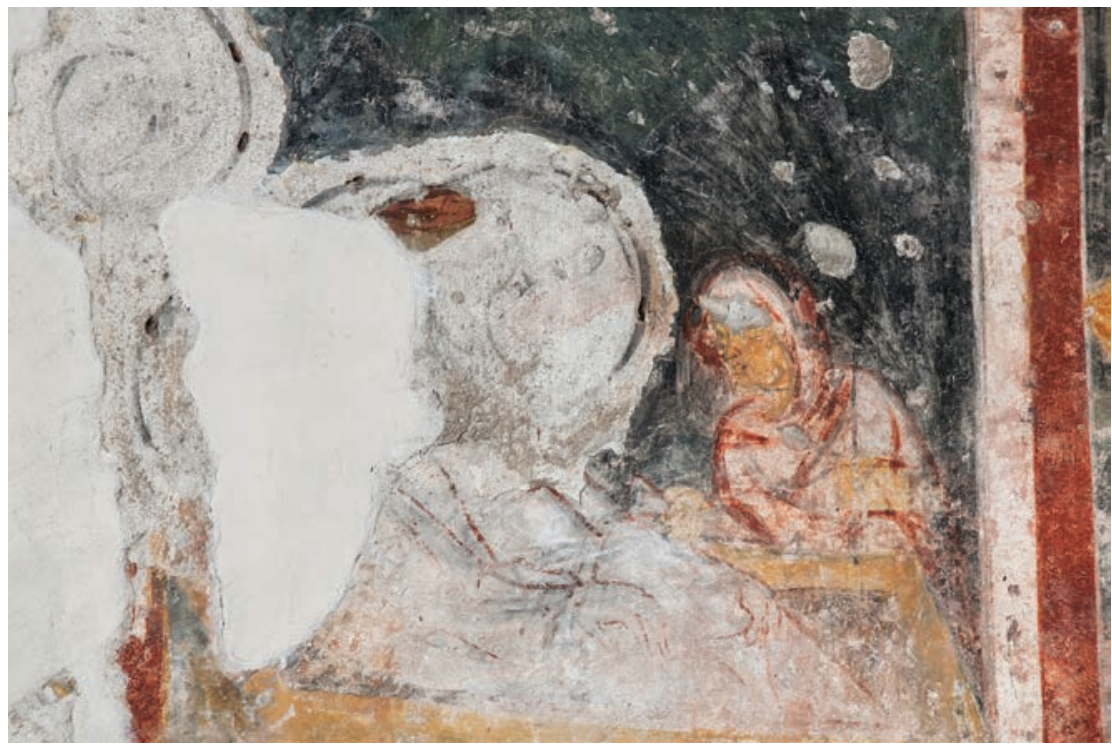

Fig. 4. Brescia, basilica di San Salvatore, parete nord, affreschi con deposizione dei corpi di Elpis, Pistis ed Agape da parte di Sophia (foto Studio Rapuzzi).

della coeva cronologia della seconda passio di Giulia - scritta per il cenobio nella prima metà del X secolo con l'aggiunta della traslazione a Brescia delle reliquie giuliane da parte di Ansa -, si può ipotizzare che i corpi di Giulia e delle tre figlie di Sophia siano pervenuti successivamente alla fondazione del monastero o siano stati enfatizzati solo in un secondo momento ${ }^{20}$. La presenza, del resto, nella cripta di ben nove corpi interi di santi (Giulia, Elpis, Pistis, Agape, Pimeneo, Ippolito, Giustissimo, due santi Innocenti e la testa di Sophia) non ha sviluppato percorsi di pellegrinaggio e nemmeno la loro diffusione cultuale ${ }^{21}$. Nonostante la martire cartaginese risulti nelle fonti l'unica santa crocifissa, la sua devozione - oltre all'area dell'alto Tirreno, dei Pirenei, delle sponde francesi e corse ${ }^{22}$-, è assai limitata e si concentra nel cenobio bresciano e in poche sue dipendenze dell'Italia centro-settentrionale ${ }^{23}$. La mancata diffusione del culto potrebbe giustificarsi con la riservatezza della devozione al cenobio e della ritualità liturgica per la comunità religiosa e gli ambienti imperiali ad essa legati ${ }^{24}$.

Nell'analisi dei martiri abbinati alla santa emerge poi una costruzione immaginifica e simbolica di nove corpora posti nelle tre arche della cripta, testimoni della fede di Cristo e emblemi delle virtù teologali e cardinali. Infatti, mentre la fede, la speranza e la carità sono interpretate dalle figlie di Sofia, le virtù cardinali - più vicine all'uomo e pilastri di una vita dedicata al bene - sono personificate da figure maschili secondo una tipologia consueta ${ }^{25}$ : Ippolito è un soldato e simboleggia la fortezza, Pimeneo è un sacerdote e rappresenta la temperanza, Giustino (o Giustissimo) è un filosofo e rimanda alla prudenza, i due Santi Innocenti uccisi da Erode rappresentano, infine, il sangue innocente versato per una giusta causa, come recita il Cantico di Zaccaria (Lc 1,6879), e pertanto designano la giustizia.

Le analisi condotte dall'équipe di Gian Pietro Brogiolo ${ }^{26}$ hanno evidenziato numerosi elementi tecnici, come la tridimensionalità delle aureole, distinte in due tipologie, documentate da Vincenzo Gheroldi ${ }^{27}$, rispetto all'omogeneità degli intonaci delle pareti delle navate. La discrepanza nelle corone sporgenti corrisponde alle due diverse aree in cui operano varie maestranze: l'una impegnata nei registri superiori, l'altra in quello inferiore vicino alle colonne. I tratti dell'architravatura, al culmine della decorazione della navata centrale, ben dialogano con i primi due registri sottostanti con le Storie di Cristo, mentre la fascia con le storie dei santi presenta moduli differenti. Questo dato conferma che nel cantiere giuliano operavano più officine: l'una distinta da caratteri ottoniani, l'altra da codici più orientali. Si rafforzano così i richiami al mondo germanico e gli stretti contatti con quello bizantino presenti nell'introduzione dei temi iconografici del racconto delle sante vergini greche, nell'importanza dell'elemento della croce e nell'utilizzo di maestranze di matrice orientale per i mensoloni prospettici - decorati con uccelli, fiori e grate - e per le figure martiriali ${ }^{28}$, i cui stilemi emergono anche dalle sinopie così vicine ai tratti degli affreschi di Castelseprio, come quelli della Fuga in Egitto.

L'indicazione cronologica "bassa" degli affreschi connessa alla presenza di maestranzegermaniche, collegate all'impero, insieme ai forti nessi orientali ${ }^{29}$, sposta la datazione verso la fine del X o meglio ai primissimi anni dell'XI secolo, nel corso dell'episcopato di Landolfo II, fratello di quell'arcivescovo milanese Arnolfo, legato ad Ottone $\mathrm{II}^{3^{\circ}}$, che individuò le radici orientali della Chiesa ambrosiana nella predicazione

di M. OLDONI, Sapienza e le sue figlie, ivi, p. XI-XVII; inoltre, A. BISANTI, Un ventennio di studi su Rosvita di Gandersheim, Spoleto, 2005 (Studi, 12); G. SCARPAT, Leggendo Rosvita e altri studi di filologia greca e latina, giudaica e cristiana, Brescia, 2010; F. STROPPA, L'immagine della martire Giulia nel complesso monastico di San Salvatore di Brescia, op. cit. (n. 3), p. 275, n. 81.

${ }^{20}$ F. STROPPA, L'immagine della martire Giulia nel complesso monastico di San Salvatore di Brescia, op. cit. (n. 3), p. 265-281; F. STROPPA, La basilica di San Salvatore: i cicli pittorici altomedievali, op. cit. (n. 2).

${ }^{21}$ Sul problema dei nove corpi deposti nella cripta si veda: n. 20.

${ }^{22}$ Ibidem.

${ }^{23}$ G. PASQUALI, L'economia delle curtes tra longobardi, bizantini e carolingi, in G. Archetti (a cura di), Desiderio. Il progetto politico dell'ultimo re longobardo, op. cit. (n. 1), p. 463-477 (con bibliografia precedente).

${ }^{24}$ F. STROPPA, La basilica di San Salvatore: i cicli pittorici altomedievali, op. cit. (n. 2).

${ }_{25}$ P. TOMEA, Intorno a Santa Giulia, op. cit. (n. 4), p. 29-102.

${ }^{26}$ Si veda in particolare i risultati delle ultime indagini G.P. Brogiolo (a cura di), Dalla corte regia al monastero, op. cit. (n. 15).

${ }^{27}$ V. GHEROLDI, Evidenze tecniche e rapporti stratigrafici, op. cit. (n. 15), p. 97-120.

${ }^{28}$ F. STROPPA, Arte e storia in Santa Maria “foris portas", in G. Archetti (a cura di), Teodolinda. I longobardi all'alba dell'Europa, Atti del Secondo convegno internazionale di studi del Centro studi longobardi (Monza, Gazzada, Castelseprio-Torba, Cairate, 2-7 dicembre 2015), Spoleto, in corso di stampa.

${ }^{29}$ Ibidem

$3^{30} \mathrm{C}$. ALZATI, Presenze e temi orientali in area italiciana dalla tarda antichità ad Ottone III, in G. Archetti (a cura di), Teodolinda. I longobardi all'alba dell'Europa, op. cit. (n. 28), in corso di stampa; M. BASSETTI, Scritture e graffiti a Castelseprio, ivi; W. HUSCHENER, Ottone III e Bisanzio: influssi e relazioni, ivi. 
dell'apostolo Barnaba ${ }^{31}$, come recita il De situ civitatis Mediolani. Nella costruzione ideologica dell'origine apostolica della Chiesa milanese - addirittura precedente quella della Roma di san Pietro, dove Barnaba sarebbe giunto prima di approdare a Milano - si ravvisano i profondi nessi tra la comunità ambrosiana e quella bresciana, confermati nella scelta da parte dell'apostolo di porre Anatalone come proto-vescovo delle due città ${ }^{32}$. Arnolfo trasse probabilmente dalla Chiesa cipriota le notizie per il De adventu Barnabae durante il suo soggiorno costantinopolitano conseguente l'incarico di accompagnare la promessa sposa di Ottone III, la principessa bizantina Zoe figlia Costantino VIII. Giunta a Bari la delegazione guidata dall'arcivescovo Arnolfo fu raggiunta dalla notizia della prematura scomparsa del giovane Ottone III, vanificando quella seconda unione benedetta da papa Silvestro II sulle orme di Ottone II e Theofano, tra la dinastia ottoniana e quella macedone. Sebbene il disegno della ricostituzione politica dell'impero romano su basi cristiane fosse venuto meno con la fine del sovrano - e un anno dopo anche quella del papa suo precettore -, Arnolfo si era nutrito della cultura orientale portando con sé oggetti preziosi, forme religiose e tradizioni cultuali di cui rimangono numerose tracce nei territori della provincia ecclesiastica milanese, che, se non sono letti con questa chiave interpretativa, perdono il loro valore storico-religioso.

È sulla base di queste motivazioni che si è giunti ad ipotizzare la programmazione di un complesso e raffinato racconto, capace di narrare attraverso figure femminili una concezione teologica imperniata sulla croce e sulla regalità imperiale, in cui Occidente e Oriente dialogano senza fratture nel tentativo di ricomporre l'ecumene cristiana. Era l'ultimo grande sforzo di un progetto politico-ecclesiastico universale medievale in cui la diarchia di papato e impero operava per uno sviluppo unitario a partire dall'Oriente della societas christiana.

\section{FONDAZIONE}

Alla base di un disegno così articolato, uno degli elementi chiave riguarda il fondatore della complessa architettura: la scelta ricade su una figura femminile, la regina Ansa ${ }^{33}$, legata ad un periodo lontano, non in competizione con l'impero ottoniano e attinente alla realtà, perché moglie del fondatore del cenobio. Da questo momento la coppia longobarda viene presa a modello e idealizzata: intorno ad essa è costituito uno sfondo metaforico che vede i due coniugi primi fautori di una politica di unificazione territoriale, la cui tradizione viene costruita successivamente, testimoniata dalla cronaca quattrocentesca di Giacomo Malvezzi ${ }^{34}$ e dal rifacimento dell'Ordinario, ripresa negli Annali della badessa Angelica Baitelli a metà del XVII secolo, nel cui catalogo la storia di Giulia e dei fondatori longobardi accompagna la descrizione delle reliquie ${ }^{35}$.

Così impostato il racconto, il riferimento alla croce ${ }^{36}$ assume un valore straordinario perché è lo strumento della morte del Cristo e simbolo della salvezza: in questa maniera si stabilisce un forte nesso con la figura di Costantino, riutilizzando la strumentalizzazione del potere della croce in hoc signo vinces, al fine di rafforzare, anche dal punto di vista del consenso e della comunicazione, una politica di unificazione tra Oriente e Occidente, che vede una nuova ricostituzione ideologica in chiave cristiana dell'impero romano, all'interno della quale, a fianco del governo politico, vi è la Chiesa di Roma le cui origini derivano da quella d'Oriente. In particolare il legame viene stretto con la figura femminile più vicina all'imperatore, la madre Elena, il cui viaggio in Terrasanta è ricordato nella Vita Costantini di Eusebio di Cesarea ${ }^{37}$, mosso dalla gratitudine nei confronti di Dio per averle concesso Costantino, come figlio e imperatore, e dalla vicinanza ai sacri luoghi calcati da Gesù, nei giorni precedenti la passione, sui quali fonda edifici architettonici che ne celebrino in modo simbolico il sito.

Il ritrovamento della vera Croce da parte di Elena è ricordato, invece, da Ambrogio nel De obitu Theodosii ${ }^{8}$ dove il presule concentra il suo racconto, non tanto sul viaggio di Elena, quanto sulla ricerca del legno sacro. La madre di Costantino, arrivata a Gerusalemme e accesa da tale religioso desiderio, trova il luogo della crocifissione colmo di detriti e, opponendosi al demonio, ne recupera i resti. Presentandosi come la nuova Maria, che mostra all'umanità il Cristo risorto,

31 L. Prosdocimi, C. Alzati (a cura di), La Chiesa ambrosiana: profili di storia istituzionale e liturgica, Milano, 1980 (Spiritualità e liturgia, 2); C. ALZATI, Ambrosianum mysterium. La Chiesa di Milano e la sua tradizione liturgica, Milano, 2000; ID., Presenze e temi orientali, op. cit. (n. 30).

${ }^{32}$ P. TOMEA, Tradizione apostolica e coscienza cittadina a Milano nel medioevo. La leggenda di San Barnaba, Milano, 1993; cfr. De situ Mediolani, I, 2.

${ }^{33}$ H. HEBLING, s.v., Ansa, regina dei longobardi, in Dizionario biografico degli italiani, 3, Roma, 1961, p. 360-361; si veda M. MARROCCHI, Ansa regina, in G. Archetti (a cura di), Desiderio. Il progetto politico, op. cit. (n. 1), p. 327-346.

${ }^{34}$ Su Giacomo Malvezzi v. G. ARCHETTI, Memorie longobarde nel "Chronicon brixianum" di Giacomo Malvezzi, in "Erat hoc sane mirabile in regno Langobardorum..." Insediamenti montani e rurali nell'Italia longobarda, alla luce degli ultimi studi, Atti del convegno di studi (Monte Sant'Angelo, 9-12 ottobre 2014), in corso di stampa; ID., Per l'onore e la libertà della patria, in G. Archetti (a cura di), Le cronache medievali di Giacomo Malvezzi, trascrizione e note di I. Bonini Valetti, Roma, 2016 (Quaderni di Brixia sacra, 7), p. 9-49; ID., "Secundum monasticam disciplinam”, op. cit. (n. 1), p. 631-68o; G. Archetti (a cura di), Le cronache medievali di Giacomo Malvezzi, op. cit. (n. 34), p. 200.

35 A. BAITELLI, Annali historici dell'edificazione, erettione et dotatione del Serenissimo monastero di S. Salvatore, et S. Giulia di Brescia, Brescia, 1657 (rist. a cura di V. Volta, Brescia, 1978).

${ }^{36}$ Sul tema vastissimo si veda per un quadro generale la voce Croce, in Enciclopedia cattolica, IV, Città del Vaticano, 1950, col. 960-964; A. FROLOW, La relique de la Vraie Croix: recherches sur le développement d'un culte, Paris, 1964; M.-CH. SEPIÈRE, L'image d'un Dieu souffrant (IX'e-X siècle), aux origines du crucifix, préface de C. Heitz, Paris, 1994; E. CAVALCANTI, S. CASARTELLI NOVELLI, M. DI BERARDO, M. DELLA VALLE, s.v., Croce, in Enciclopedia dell'arte medievale, Roma, 1994, p. 529-557; G. JÁSZAI, s.v., Crocifisso, ivi, p. 577-586; Christs en croix romans, Textes médiévaux traduits par É. de Solms, Saint-Léger-Vauban, 1995; G. Rossetti (a cura di), Santa Croce e Santo Volto: contributi allo studio dellorigine e della fortuna del culto del Salvatore (secoli IX-XV), Pisa, 2002 (Piccola biblioteca GISEM, 17); C. MERCURI, Corona di Cristo, corona di re. La monarchia francese e la corona di spine nel medioevo, Roma, 2004 (Centro alti studi in scienze religiose, 2); J.-M. PRIEUR, La croix chez les Pères (du II au début du IVe siècle), Strasbourg, 2006 (Cahiers de Biblia Patristica, 8); B. Ulianich (a cura di), La croce. Iconografia e interpretazione (secoli I-inizio XVI), Atti del convegno internazionale di studio (Napoli, 6-11 dicembre 1999), 3 voll., Roma-Napoli, 2007; G. CHAUVIN, La crucifixion: autour du septénaire onto-cosmologique. Histoire, iconologie et théologie, Paris, 2011. ${ }^{37}$ EUSEBIO DI CESAREA, Sulla vita di Costantino, a cura di L. Tartaglia, Napoli, 1984.

${ }^{3} 8$ SANCTI AMBROSII mediolanensis episcopi De obitu Theodosii oratio, in Patrologia latina, 16, col. 1399-1402. 
individua la Croce grazie al titulus, fatto realizzare da Pilato, e ai chiodi della crocifissione che, inverando l'antica profezia di Zaccaria ${ }^{39}$, consegna al figlio per esaltarne la religiosità, ponendoli uno nel diadema e l'altro nel freno del cavallo: in tal modo il pensiero e la mano dell'imperatore sarebbero stati guidati da Dio. L'excursus ambrosiano, collocato nel contesto dell'orazione funebre per Teodosio, vuole giustificare il diritto del giovanissimo Onorio al regno in nome della hereditas fidei che, simboleggiata dalla trasmissione dei chiodi, è il principio su cui, da Costantino in poi, si fonda la trasmissione di un potere legittimato appunto dalla fede.

In questo modo Flavia Giulia Elena Augusta ${ }^{40}$ - nel cui nome tramanda quello della santa del cenobio bresciano diventa un exemplum da seguire al punto che l'artificio dell' $i$ mitatio Helenae si riscontra nei racconti di reali e imperatori - da Atenaide Eudocia, sposa di Teodosio II, a Galla Placidia, da Radegonda di Turingia a Sofia, moglie dell'imperatore Giustino $^{41}$ - al fine di rivendicare una sorta di regale ascendenza a Costantino, emulandone gli atteggiamenti come la fondazione di nuove chiese, il sostegno al pellegrinaggio ai luoghi santi e la stretta relazione con la croce.

La mimesi con Elena affiora anche nel caso di Ansa riflettendo il calco con la figura della madre dell'imperatore che la storiografia antica vede fondatrice della basilica della Natività e di quella del Monte degli Ulivi in Terrasanta, come fa Costantino con la basilica del Santo Sepolcro a Gerusalemme. Infatti nella passio II di santa Giulia si rintraccia la prima menzione della traslazione del suo corpo dall'isola della Gorgona a Brescia, per opera della regina longobarda, che mossa da un irrefrenabile desiderio ${ }^{42}$, come Elena, opera con tutte le sue forze per realizzare un monumento consono a conservare degnamente le reliquie giuliane.

La vicenda della vera Croce ${ }^{43}$ non può essere slegata da Gerusalemme, luogo in cui la versione più nota in occidente, quella di Ambrogio, tramanda che la madre di Costantino ripartisse il sacro legno tra la Città santa e Costantinopoli:
Elena, tuttavia, avrebbe riportato un frammento di croce anche a Roma, custodita nel palazzo Sessorio ${ }^{44}$ che diventerà la cappella, chiamata de Hierusalem, la cui dedicazione compare anche nel cenobio giuliano. Dopo Costantino frammenti della Croce si diffusero in tutta la cristianità: infatti, sia Cirillo vescovo di Gerusalemme sia Paolino di Nola testimoniano in diversi luoghi la loro venerazione, come pure la storiografia bizantina narra trasferimenti di pezzi lignei sotto Teodosio II e Giustino II, il quale inviò al pontefice una reliquia del sacro legno in una stauroteca a forma di croce: la Crux Vaticana ${ }^{45}$ gemmata sulla fronte e sbalzata sul retro con i ritratti del sovrano Giustino e della moglie Sofia, ancora conservata nel tesoro di San Pietro, modello antico sulla base del quale vengono predisposte numerose oreficerie, come ad esempio la croce detta di Desiderio.

Elementi tratti dalla vita di Elena, ripresi nelle azioni di Ansa e ricordati nella storiografia, emergono dalla più antica biografia della madre di Costantino, Vita seu potius homilia de Sancta Helena ${ }^{46}$, composta a metà IX secolo su incarico di Incmaro di Reims dal monaco Almanno di Hautvillers, per celebrare l'arrivo delle reliquie nel suo monastero. Questi, avendo poche notizie a disposizione, ne costruisce l'elogio: se l'inventio crucis è l'avvenimento più significativo della vita di Elena, non mancano altri episodi come l'abbandono del giudaismo per influenza di papa Silvestro o il banchetto da lei servito alle ancelle di Dio a Gerusalemme. Su questo schema anche la tradizione giuliana tramanda il ricordo del giorno della morte della regina longobarda, durante il quale veniva offerta una razione di pane e vino ai poveri accorsi numerosi in quel giorno festivo ${ }^{47}$.

Alla luce di quanto indicato la funzione della fascia purpurea (fig. 5), realizzata alla base delle sequenze pittoriche della navata basilicale, ben si legge all'interno della interpretazione del potere spirituale in collegamento con quello imperiale. La critica ${ }^{48}$ ha offerto due versioni leggendo «RE-

\footnotetext{
${ }_{39}$ Zac 14,20: «In illo die erit, quod super frenum equi, sanctum domino omnipotenti».

${ }^{40}$ EUSEBIO DI CESAREA, Sulla vita di Costantino, op. cit. (n. 37); si veda anche D. DAINESE, La Vita e le Laudes Constantini. Presentazione e analisi di testi problematici, in Enciclopedia costantiniana, II, Roma, 2013, p. 91-115; I. BALDINI, Arte e iconografia costantiniane, ivi, II, 787-792; G. BONAMENTE, Costantino fra divinizzazione e santificazione, ivi, II, p. 5-30; F. GUIDETTI, Iconografia di Costantino. L'invenzione di una nuova immagine imperiale, ivi, II, p. 185-200. Si veda inoltre F.E. CONSOLINO, Elena. De stercore ad regnum, ivi, I, p. 117-133. Si veda inoltre A. AMORE, E. CROCE, M.V. BRANDI, s.v. Costantino, imperatore, in Bibliotheca sanctorum, IV, Roma, 1964, col. 237-249.

${ }^{41}$ Cfr. n. 40.

${ }^{42}$ F. STROPPA, Le immagini e gli usi del pane nel medioevo, in G. Archetti (a cura di), La civiltà del pane, op. cit. (n. 10), p. 1293-1301 (con bibliografia precedente); EAD., La basilica di San Salvatore: i cicli pittorici altomedievali, op. cit. (n. 2), passim.

${ }^{43}$ M. DELLA VALLE, La croce in Occidente. Il simbolo e il monogramma, in Enciclopedia costantiniana, op. cit. (n. 40), I, p. 231-246; ID., La croce in Oriente, ivi, II, p. 667-681. Per la leggenda della vera Croce: B. BAERT, La leggenda della vera Croce e la sua iconografia (VIII-XV secolo). La disseminazione dei cicli figurativi in prospettiva europea, ivi, II, p. 683-697; L. BEVILAQUA, Reliquie e basiliche, ivi, II, p. 699-712.

${ }^{44} \mathrm{Nel}$ Liber pontificalis si narra che a Roma, a lato del palazzo Sessoriano, venne edificata la chiesa di Santa Croce in Gerusalemme, già chiamata Basilica Heleniana. Elena risiedette a Roma per parecchi anni: cfr. D. COLLI, Il palazzo Sessoriano nell'area archeologica di S. Croce in Gerusalemme: ultima sede imperiale a Roma?, in Mélanges de l'École française de Rome. Antiquité, CVIII, 2 (1996), p. 771-815; F.E. CONSOLINO, Elena. De stercore ad regnum, op. cit. (n. 40), p. 117-133; cfr. n. 43.

${ }^{45}$ M. DELLA VALLE, La croce in Occidente, op. cit. (n. 43), p. 231; V. PACE, G. SANTE, P. RADICIOTTI, La Crux Vaticana o croce di Giustino II. Museo storico artistico del tesoro di San Pietro, Città del Vaticano, 2009.

${ }^{46}$ ALMANNUS ALTAVILLARENSIS, Epist. III, in Acta sanctorum, Augusti, III, p. 580-599, in part. 581 C.

${ }^{47}$ Cfr. n. 40, 42.

${ }^{48}$ Sul tema si è dedicata Flavia De Rubeis, cfr. EAD., Desiderio re o Ludovico imperatore?, in Museo della città, Brescia, op. cit. (n. 15), p. 103-104; EAD., La scrittura epigrafica in età longobarda, in C. Bertelli, G.P. Brogiolo (a cura di), Il futuro dei longobardi, op. cit. (n. 8), p. 71-83; EAD., Desiderio re, la regina Ansa, in Dalla corte regia al monastero di San Salvatore - Santa Giulia di Brescia, op. cit. (n. 15), p. 89-96; in precedenza Bernard Bischoff suggerisce a Gaetano Panazza la lettura «regnantem Desiderium» [cfr. G. PANAZZA, La basilica di San Salvatore in Brescia, in Arte lombarda, V, 2 (1960), p. 161-186, in part. p. 165] a cui si aggiunge «Tiro Hlu[dovicus]», riferendosi all'imperatore Ludovico II "eroe" (cfr. G. PANAZZA, Gli scavi, l'architettura e gli affreschi della chiesa di San Salvatore in Brescia, in La chiesa di San Salvatore in Brescia, Atti dell'ottavo congresso di studi sull'alto medioevo, II, Milano, 1962, p. 5-228, in part. p. 95). Si veda anche G.P. BOGNETTI, Brescia carolingia, in Storia di Brescia, I, Brescia, 1961, p. 458-459; a questa lettura di contrappone A. WEIS, Die langobardische Königsbasilika von Brescia: Wandlungen von Kult und Kunst nach der Rombelagerung von 756, Sigmaringen, 1977, p. 18-19; alla
} 


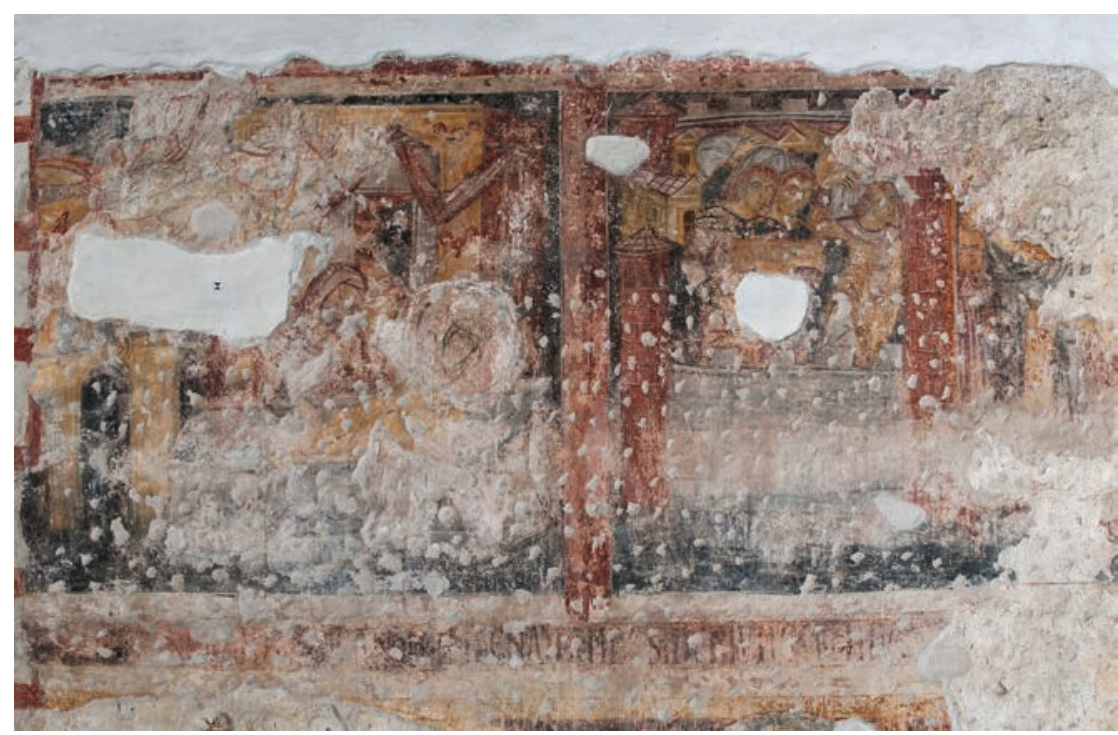

Fig. 5. Brescia, basilica di San Salvatore, parete sud, affresco con deposizione di un corpo in un sarcofago (a sinistra), trasporto di una salma da una città (a destra), scritta purpurea, in basso (foto Studio Rapuzzi).

GNANTEM DESIDERIUM TIRO HLU[DOVICUS]» oppure «[---] SANO [---] REGNANTEM DESIDERIUM [C]UM CONIU[GE SUA ANSA --->: non mi addentro nell'analisi che appare complessa a causa della caduta dei pigmenti, tuttavia, appoggiandosi ai dati emersi, appare evidente che la porpora dello sfondo del nastro tradisce un messaggio celebrativo della fondazione cenobitica. Il riferimento a Desiderio potrebbe essere stato posto sotto le storie della santa dedicataria in cui si narrano i fatti principali e forse la traslazione a Brescia, avvenuta durante il suo regno: infatti, nella seconda passio di Giulia il nome del re viene usato in eleganti figure retoriche che giocano sul doppio significato, come nome proprio ma anche come sostantivo che implica l'aspirazione a qualcosa, appunto il desiderio.

Giunti a questo livello, se si concorda con la prima lettura, l'aggettivo tirus può significare giovane, ma anche tyrus, cartaginese, dato che siamo posti sopra la raffigurazione di una città, che può identificarsi con quella natia della santa. Se ci si basa, invece, sulla seconda lectio la nuova interpretazione avvalora quanto sostenuto sullo spostamento della datazione degli affreschi al X secolo, dato che l'intervento della regina Ansa è evidente solo da questo periodo - mentre in precedenza la fondazione è legata al solo re Desiderio $^{49}$ - e dato che il termine coniunx appare dal periodo carolingio in avanti in sostituzione del lemma regina, più usato in età longobarda, come ha messo in luce Cristina La Rocca ${ }^{50}$.

Le due versioni tuttavia non contrastano con il messaggio visivo della narrazione delle sequenze pittoriche che affida tanto all'immagine quanto al testo scritto la lettura del fedele fondata su più livelli interpretativi: l'abbreviazione della scritta, dunque, se legata ad una visione completa del palinsesto giuliano ${ }^{51}$, date le premesse, potrà dare ulteriori frutti.

\section{STRUTTURE CENOBITICHE}

La ricchezza delle proprietà e la sfarzosa narrazione simbolica del monastero corrispondevano anche alla pingue dote di preziosi reliquiari - come la lipsanoteca ${ }^{2}$ - e di numerose croci53 che venivano conservate nella chiesa di Santa Maria in Solario. Spetta a Gabriele Archetti ${ }^{54}$ l'individuazione, attraverso le fonti documentarie, degli spazi di vita della comunità monastica e dei percorsi liturgici seguiti da processioni corredate di croci, realizzate per benedire gli ambienti, per celebrare le festività: come quella pasquale, dei santi venerati nel cenobio e della Santa Croce, tramite il ricordo dell'invenzione ${ }^{55}$ ( 3 maggio) e della esaltazione ${ }^{56}$ (14 settembre). I percorsi si snodano nell'intero complesso claustrale, attraverso anche i luoghi di uso quotidiano, come i dormitori o le cucine, ma nella maggior parte dei casi gli spostamenti processionali si concentrano nella basilica di San Salvatore e successivamente, dalla fine del XII secolo, anche in Santa Maria in Solario.

Prima di addentrarci nel breve excursus sulla disposizione degli altari è importante puntualizzare la dislocazione degli ambienti basilicali e la nuova interpretazione degli scavi, emersa attraverso l'incrocio dei dati forniti dall'ultimo studio di Gian Pietro Brogiolo e dai giornali di scavo di Ignazio Guarnieri ${ }^{57}$, che delineano - se uniti agli elementi tratti dalle fonti storiche, storiografiche, agiografiche e liturgiche, di cui finora non si è ben tenuto conto - un nuovo assetto della basilica, differente dalle soluzioni di Gaetano

lettura di Ludovico II si oppone quella di Lotario proposta da Florentine Mütherich durante la discussione al seminario internazionale del 1981 [Seminario internazionale sulla decorazione pittorica del San Salvatore di Brescia, Atti (Brescia, 10-20 giugno 1981), Pavia, 1983, p. 80-81] e in seguito accolta da Werner Jacobsen: cfr. ID., San Salvatore in Brescia, in K. Bierbrauer, P. K. Klein, W. Sauerländer (hrsg.), Studien zur mittelalterlichen Kunst. 8oo-1250. Festschrift für Florentine Mütherich zum 7o. Geburtstag, München, 1985, p. 75-8o.

49 Sulla questione G. ARCHETTI, "Secundum monasticam disciplinam”, op. cit. (n. 1), p. 631-680.

${ }^{50} \mathrm{C}$. LA ROCCA, Monachesimo femminile e poteri delle regine tra VIII e IX secolo, in G. Spinelli (a cura di), Il monachesimo italiano dall'età longobarda all'età ottoniana (sec. VII-X), Atti del VII convegno internazionale di studi storici sull'Italia benedettina (Nonantola, 10-13 settembre 2003), Cesena, 2006, p. 126-127. ${ }^{51}$ F. DE RUBEIS, Desiderio re, la regina Ansa, op. cit. (n. 48), p. 89-95.

${ }^{52}$ Per una descrizione generale dell'opera si veda: G. VEZZOLI, Scheda VIII.oz. Lipsanoteca (reliquiario), in San Salvatore di Brescia. Materiali per un museo, I, op. cit. (n. 4), p. 174-175; C. STELLA, La lipsanoteca, in R. Stradiotti (a cura di), San Salvatore - Santa Giulia a Brescia, op. cit. (n. 1), p. 347-353. Rituale, f. 3or: «Et hoc facto ebdomodaria epistula teneat sepulcrum eboris in manibus in medio choro donec expleat epistulam et incipiat officium misse».

${ }^{53}$ A. BAITELLI, Annali historici, op. cit. (n. 35), p. 7-14; inoltre G. ARCHETTI, Per la storia di S. Giulia nel medioevo, op. cit. (n. 1), p. 27; ID., Vita e ambienti del monastero, op. cit. (n. 1), p. 127.

${ }^{54}$ Cfr. n. 1.

55 Rituale, f. 19.

${ }^{56}$ Rituale, f. $23 \mathrm{v}$.

${ }^{57}$ Cfr. Brescia, Archivio storico dei civici Musei di arte e storia, GuARnieri, Giornale di scavo, diario - chiesa di San Salvatore; diario - atrio quattrocentesco; diario - cripta, 1957-1959. 
Panazza e di Brogiolo. Lo snodo della questione verte intorno ai lacerti di una evidenza muraria che si sviluppa ad est e ad ovest dell'attuale muro di facciata.

Nei pressi della porta di ingresso alla basilica, gli scavi hanno rilevato le fondazioni di una struttura simile ad un protiro che ha una corrispondenza anche all'interno della chiesa $^{58}$ : le tracce di questa intelaiatura ancora non ben identificata dalla critica ${ }^{59}$ potrebbero far pensare ad una struttura architettonica non troppo alta, data la fondazione, che costituiva un'enfasi del corpo occidentale della chiesa e che alla luce dei dati emergenti dai documenti archivistici e da quelli materiali potrebbe suggerire l'esistenza di una cappela in collegamento con l'area dell'attuale sottocoro che aveva funzione funeraria, simile alla galilea ${ }^{60}$. Essa era un ambiente basilare nella struttura di Cluny II ${ }^{61}$ (955-1040) in cui venivano celebrate le messe per i defunti che avevano elargito donazioni al cenobio o erano legati da fraternità con la comunità dei monaci. Ad enfatizzarne la funzione vi è la sua posizione all'interno della chiesa, opposta all'altare maggiore, e a ridosso della controfacciata, dove di norma si colloca la decorazione del Giudizio universale. Anche i percorsi liturgici rendono speciale questo spazio: infatti fin dall'VIII secolo, nella domenica di Resurrezione alcune comunità cenobitiche, nell'itinerario processionale tra gli ambienti, dedicavano una stazione davanti al portale prima di tornare in coro, come viene anche ribadito nel Rituale del cenobio bresciano $^{62}$.

Dai percorsi registrati nel Rituale, dagli altari presenti in basilica, dalle ultime indagini ${ }^{63}$ del riesame del giornale di scavo di Ignazio Guarnieri e dalle carte di restauro si è compreso che lo spazio della basilica dovesse essere molto più ampio, comprendendo l'attuale con l'aggiunta del sottocoro che aveva funzione cimiteriale ${ }^{64}$. Ad ovest la chiesa era anticipata da un atrio e si espandeva verso est sviluppandosi in due blocchi, il primo aperto ai fedeli (sottocoro) e il secondo (basilica) riservato alla clausura, per concludersi nell'area absidale corredata da una cripta che ospitava tre arche, contenenti nove corpi integri che, paragonabili alle nove muse se lette in chiave cristiana come presenta uno dei cammei della croce di Desiderio, mostrano il punto d'arrivo per il monaco. I nove exempla rappresentano l'itinerario della vita del buon cristiano il quale, seguendo l'esempio di Giulia, poteva giungere alla salvezza, al termine della vita terrena, solo se essa fosse stata condotta secondo le virtù cardinali, sorretta dai principi teologali e illuminata dalla Sapienza divina.

La basilica era caratterizzata dal coro monastico, che comprendeva l'attuale navata centrale, e da numerosi altari dedicati, tra gli altri, ai santi Sebastiano e Fabiano, a san Vincenzo, a san Gregorio, alla Trinità, alla beata Vergine, mentre spazi più ampi erano riservati alle cappelle di San Giovanni Battista e di San Nicola atte a ospitare la comunità per i riti del battesimo e, in taluni casi, anche le riunioni del capitolo ${ }^{65}$.

Tra le sacre mense del cenobio ve ne sono alcune degne di particolare attenzione per la funzione liturgico-simbolica che le connotava e per gli spostamenti processionali che ne scaturivano. Laltare di San Michele ${ }^{66}$ era collocato nella zona aperta ai fedeli, cioè l'attuale sottocoro, ambiente caratterizzato da una destinazione funeraria che ben si addiceva alla funzione religiosa dell'arcangelo, quale psicopompo: in particolare esso era posizionato nella porzione sud del corpo occidentale della basilica poiché aveva un collegamento diretto con il dormitorio, ad esso intitolato, posto nei chiostri a meridione della chiesa.

La sacra mensa di Sant'Elena era anch'essa sul lato sud tuttavia in fondo alla basilica, accanto alla porta laterale che da una parte dava verso l'atrio esterno, e dall'altra verso l'area «pubblica» della chiesa destinata in occasioni particolari dell'anno liturgico ad accogliere i fedeli «per la celebrazione della messa del popolo» ${ }^{67}$. Nel complesso vi era pure l'altare dedicato agli Apostoli - che rinvia alla basilica Apostolorum

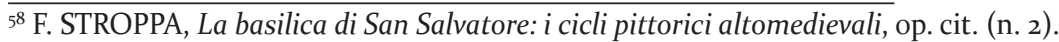

59 G.P. BROGIOLO, Archeologia e architettura delle due chiese di San Salvatore, in G.P. Brogiolo (a cura di), Dalla corte regia al monastero, op. cit. (n. 15), p. 49-50.

${ }^{60}$ F. STROPPA, Le rotonde, le torri e le reliquie nella diocesi di Brescia, in A.C. Quintavalle (a cura di), Medioevo: le officine, Atti del XII convegno internazionale di studi (Parma, 22-27 settembre 2009), Milano, 2010, p. 411-419, p. 417 nota 2, in part. si vedano i riferimenti a Kristina Krüger e ad Anne Baud: K. KRÜGER, Tournus et la fonction des galilées en Bourgogne, in C. Sapin (a cura di), Avant-nefs E espaces d'accueil dans l'église (épuisé) entre le IVe et le XII siècle, Paris, 2002, p. 414-423; A. DIERKENS, Avant-corps, galilées, massifs occidentaux: quelques remarques méthodologiques en guise de conclusions, ivi, p. 495-503; K. KRÜGER, Die romanischen Westbauten in Burgund und Cluny: Untersuchungen zur Funktion einer Bauform, Berlin, 2003; EAD., Architecture and liturgical practice: the cluniac "Galilaea", in N. Hiscock (ed. by), The white mantle of churches: architecture, liturgy, and art around the Millennium, Turnhout, 2003 (International medieval research. Art history, 10), p. 138-159; EAD., La fonction liturgique des galilées clunisiennes: les exemples de Romainmôtier et Payerne, in N. Bock, P. Kumann (sous la direction de), Art, cérémonial et liturgie au Moyen Âge, Actes du colloque de $3^{\mathrm{e}}$ cycle Romand de Lettres (Lausanne-Fribourg, 24-25 mars, 14-15 avril, 12-13 mai 2000), Rome, 2002, p. 169-190; A. BAUD, Cluny, un grand chantier médiéval au coeur de l'Europe, Paris, 2003, p. 164-184; EAD., La chapelle de l'abbé et le passage Galilée à Cluny: les sources graphiques et textuelles à l'épreuve de l'archéologie, in P. Bernardi, A. Hartmann-Virnich, D. Vingtain (sous la direction de), Texte et archéologie monumentale: approches de l'architecture médiévale, Actes du colloque centre international de congrès (Avignon, Palais des Papes, 30 novembre, $1^{\text {er }}$ et 2 décembre 200o), Montagnac, 2005 (Europe médiévale, 6), p. 58-65. Si veda per la parte rituale F.S. PAXTON, The death ritual at Cluny in the central Middle Ages, Turnhout, 2013 (Disciplina monastica, 9).

${ }^{61}$ Si veda G. ARCHETTI, Medioevo cluniacense. Monaci, chiese e priorati nel territorio bresciano, in Civiltà bresciana, XV, 1-2 (2006), p. 9-58; ID., Fraternità, obbedienza e carità. Il modello cluniacense, in G. Andenna (a cura di), A servizio del Vangelo. Il cammino storico dell'evangelizzazione a Brescia, 1. L'età antica e medievale, Brescia, 2010, p. 483-513, 654-659 (con bibliografia precedente).

${ }^{62}$ F. STROPPA, L'immagine di Cluny nelle architetture delle fondazioni lombarde, in P. Galetti (a cura di), "Fondare" tra antichità e medioevo, Atti del convegno di studio (Bologna, 27-29 maggio 2015), Spoleto, 2016 (Incontri di studio, 14), p. 305-330; come pure F. STROPPA, La basilica di San Salvatore: i cicli pittorici altomedievali, op. cit. (n. 2).

${ }_{63}$ F. STROPPA, La basilica di San Salvatore: i cicli pittorici altomedievali, op. cit. (n. 2).

${ }^{64}$ Sulle ultime indagini si vedano G. ARCHETTI, "Secundum monasticam disciplinam", op. cit. (n. 1); come pure F. STROPPA, La basilica di San Salvatore: $i$ cicli pittorici altomedievali, op. cit. (n. 2).

${ }^{65}$ Sulla questione si vedano i testi di Archetti, cfr. n. 1.

${ }^{66}$ Individuato da G. ARCHETTI, Per la storia di Santa Giulia nel medioevo, op. cit. (n. 1), p. 25-26; ID., Vita e ambienti del monastero, op. cit. (n. 1), p. 116, 124.

${ }^{67}$ Rituale, f. $38 \mathrm{v}$.
} 


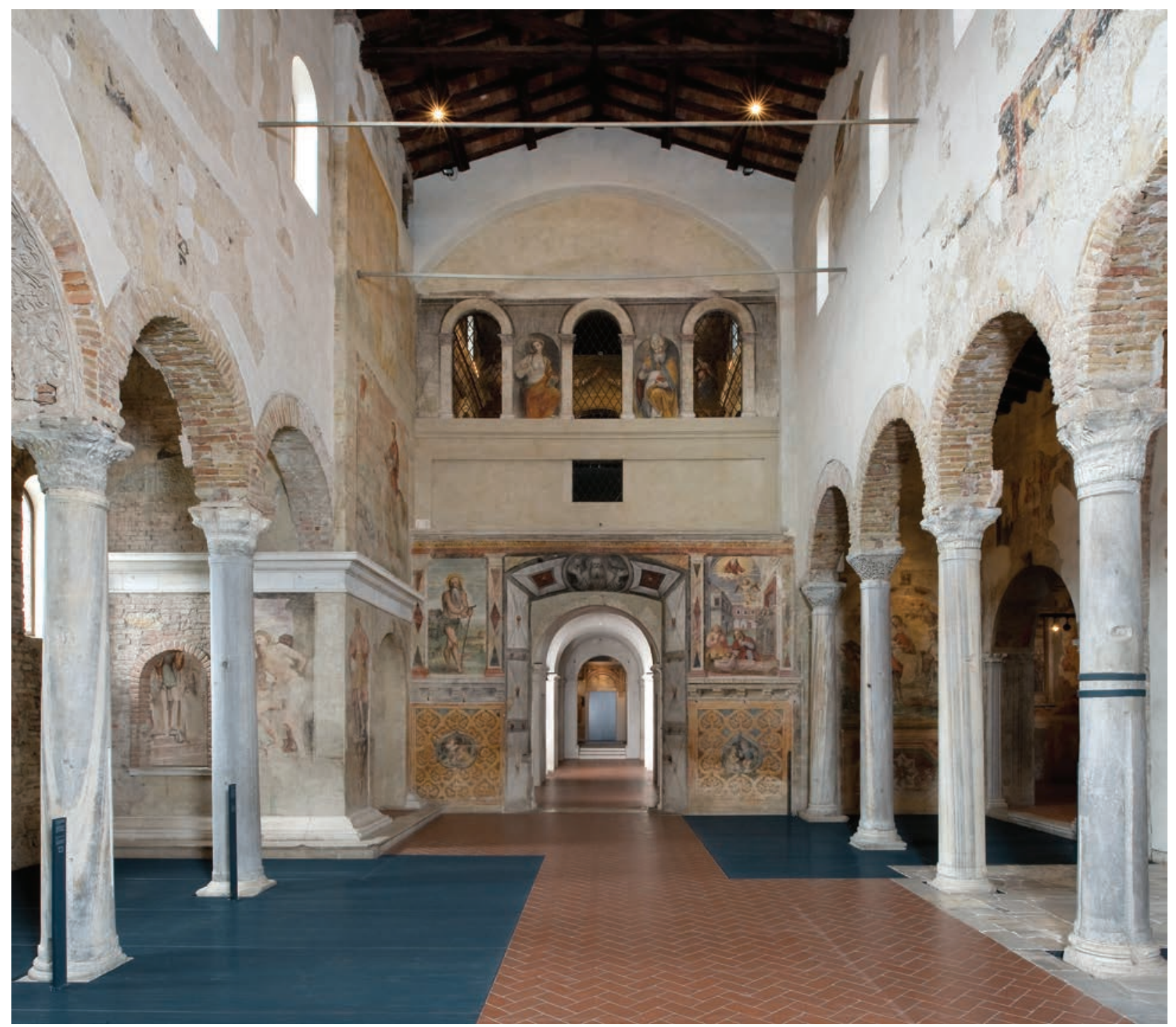

Fig. 6. Brescia, basilica di San Salvatore (foto Studio Rapuzzi).

di Costantinopoli e di Milano - e quello di Santa Maria de Hierusalem $^{68}$ che nel Rituale e nelle fonti documentarie viene ricordato nel campanile ${ }^{69} \mathrm{e}$ la cui dedicazione richiama la cappella realizzata da Elena nel palazzo Sessorio a Roma.

Dai dati archeologici è difficile comprendere dove fosse collocata: non sappiamo se l'attuale struttura campanaria, databile alla fine del XII secolo, sia stata innalzata su una precedente torre oppure se i resti nella zona centrale della controfacciata (fig. 6) possano essere la testimonianza di una intelaiatura che accoglieva la cappella de Hierusalem nel mezzo della chiesa - riconducibile ad un sacello fune- rario di particolare valore simbolico in connessione alla Galilea - in corrispondenza con il termine della clausura.

La presenza nel cenobio di una cappella detta de Hierusalem $^{70}$, di un frammento della Croce e di un ricco nucleo di reliquie inerenti i luoghi del Santo Sepolcro e gli oggetti della passione di $\mathrm{Cristo}^{71}$ suggerisce uno stretto collegamento con la basilica Heleniana di Roma e l'Anastasis di Gerusalemme, delineando una cappella vicina all'area cimiteriale in una posizione mediana che rappresentava un nesso ad est con la cripta, dove riposavano le spolia di Giulia, e ad ovest con l'altare di Elena ${ }^{72}$, la cui menzione

\footnotetext{
${ }^{68}$ Cfr. n. 43, 69, 70.

${ }^{69}$ G. ARCHETTI, Per la storia di Santa Giulia nel medioevo, op. cit. (n. 1), p. 25-26; ID., Vita e ambienti del monastero, op. cit. (n. 1), p. 116,124

${ }^{70}$ Rituale, 6r, 15v, 37v, 37r, 39r.

${ }^{71}$ A. BAITELLI, Annali historici, op. cit. (n. 35), p. 7-14. Nel monastero vi erano numerosi frammenti provenienti dai luoghi del martirio del Cristo, come un pezzo della vera Croce; due spine della corona di Gesù (che rinverdiscono al momento dell'incoronazione); un legno della corona di spine; un pezzo della spugna del martirio di Gesù; un brandello del sudario, della colonna della flagellazione, del sepolcro, della pietra del monte degli Ulivi dove Gesù ascende al cielo, ecc. Vi sono anche sacri resti del monte Tabor, dove Cristo trasfigurò; come pure i resti della santa Casa, i capelli, il latte, il filo, il manto, i vestimenti e il sepolcro della beata vergine Maria; Santa Sion. Compaiono reliquie relative ai miracoli di accompagnamento all'istituzione dell'eucarestia nell'Ultima Cena: si conservava un frammento della tavola, un pezzo di una delle brocche delle nozze di Cana, che contenevano l'acqua tramutata in vino, e i frammenti dei pani e dei pesci dell'omonimo miracolo.

${ }^{72}$ Rituale, f. 33r: «In festo Sanctae Crucis cantetur missam in Sancta Helena»; f. 38r «In vigilia inventionis Sanctae Crucis eundo ad ecclesiam Sanctae Elene»; f. $38 \mathrm{v}$ «In vigilia exaltationis Sanctae Crucis post vesperum eundo cum processione in Sancta Elena cum cereis accensis cantetis (...), in mane presbiteri dicant missam populi in Sancta Elena»; f. 24v: «In dedicatione ecclesiae Sancte Iuliae quando incipit ad pulsandum vesperum vadant omnes domine in ecclesia Sanctae Elenae (...). Finito isto vespero domine vadant in ecclesia magna cum processione cum cereis et candelis accensis canentes hunc responsorium "fundata est" (...). Et dicatis in die festo similiter vesperum in Sancta Elena dum pulsatur».
} 


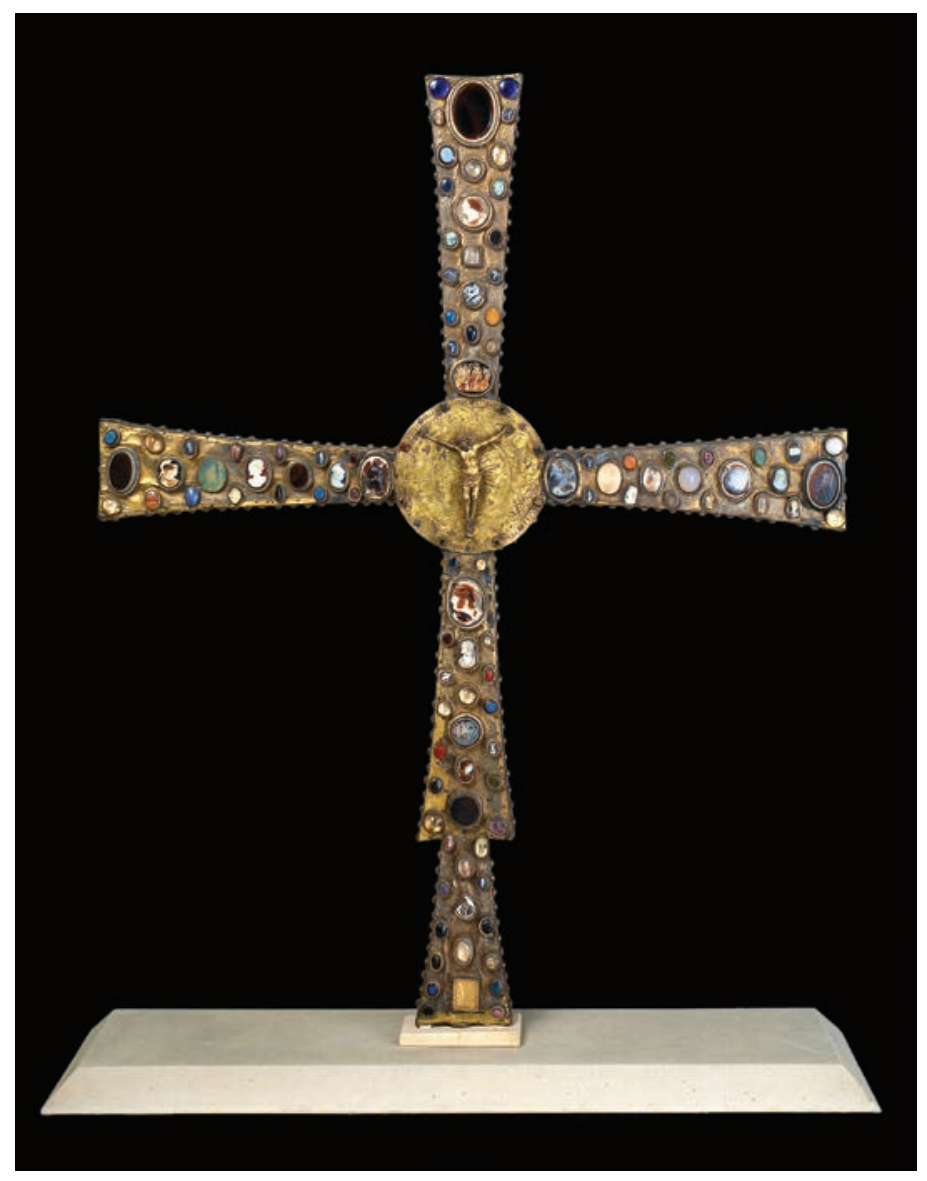

Fig. 7. Brescia, Santa Maria in Solario, croce di Desiderio, recto (foto Studio Rapuzzi).

nel Rituale è costantemente abbinata alla celebrazione della croce.

Appare evidente, alla luce di questi dati, che le ipotesi presentate da Gian Pietro Brogiolo ${ }^{73}$ sulla collocazione della cappella de Hierusalem nell'area sud-est del chiostro centrale siano poco condivisibili anche solo per la funzione così particolare e altamente simbolica che doveva svolgere all'interno della basilica. Il posizionamento di Brogiolo svilisce il compito di sacro contenitore delle reliquie del Santo Sepolcro e dei luoghi della Terrasanta, obliterando la sacralità e la gerarchizzazione dei siti, fondamentale in età medievale. La struttura del chiostro individuata da Brogiolo e scambiata per Santa Maria di Gerusalemme non è altro che la fontana monumentale del chiostro destinata alle abluzioni monastiche ${ }^{74}$.

A questo punto meglio si spiega anche la tomba di Ansa, derivata dal racconto malvezziano, che la critica, appoggiandosi al riferimento letterario del luogo di tumulazione "presso il campanile", individua nella struttura archivoltata della pare-

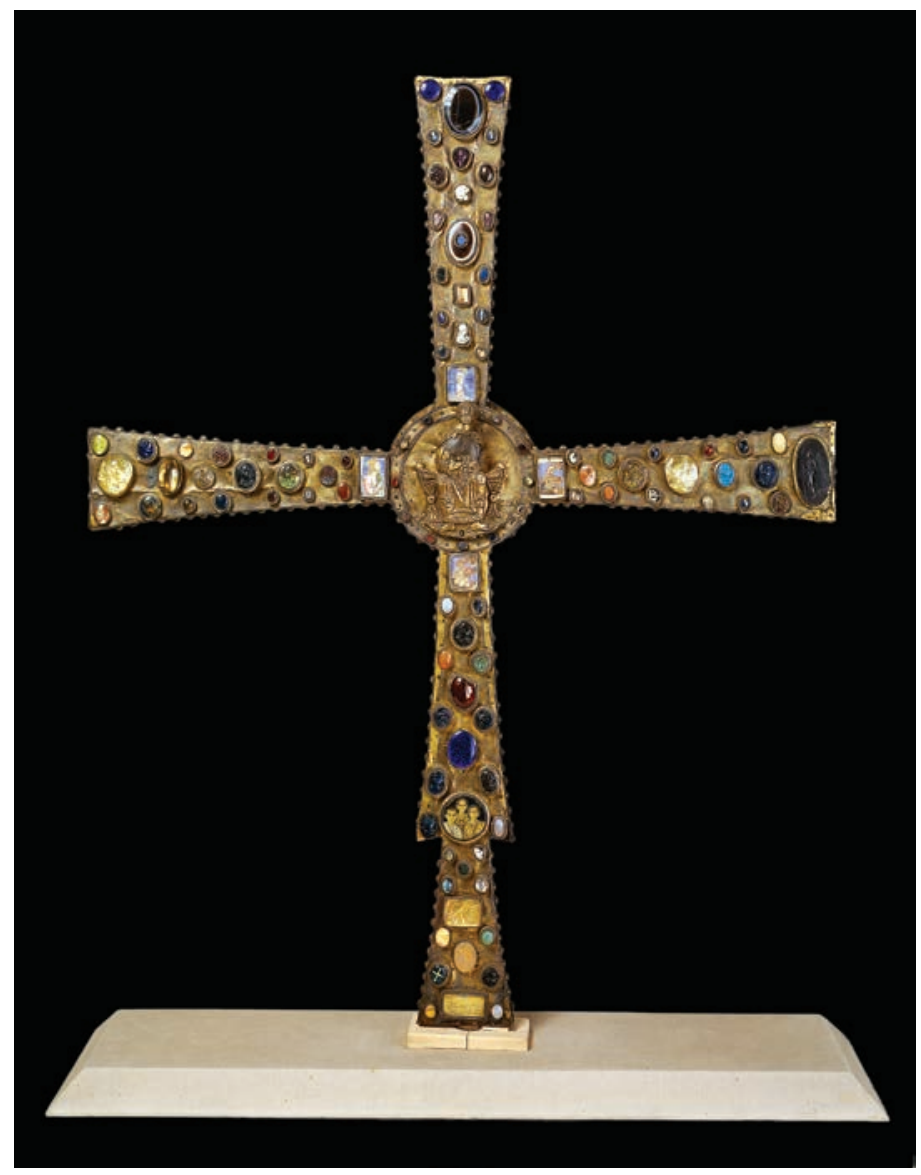

Fig. 8. Brescia, Santa Maria in Solario, croce di Desiderio, verso (foto Studio Rapuzzi).

te sud della basilica, che rappresenta invece l'ingresso laterale della chiesa al chiostro. Come già spiegato la tradizione del cenobio ricorda il giorno di sepoltura e le celebrazioni all'altare dei Santi Fabiano e Sebastiano che identifica appunto la cappella de Hierusalem, adiacente all'area cimiteriale come luogo più consono per la commemorazione della fondatrice ${ }^{75}$.

Oltre a questi elementi rimangono tracce anche degli arredi liturgici che avevano come elemento principale la croce, la più conosciuta è probabilmente quella, denominata di re Desiderio ${ }^{76}$ (figg. 7,8 ), custodita nell'aula inferiore di Santa Maria in Solario insieme agli oggetti più preziosi del cenobio, ossia alla documentazione economico-patrimoniale e al tesoro delle croci, per essere usata in solenni occasioni come nel caso dell'ostensione pubblica del Venerdì Santo ${ }^{77}$. La grande croce monumentale veniva portata in processione lungo i percorsi che si snodavano tra la chiesa di Santa Maria in Solario, San Salvatore, Santa Maria de Jerusalem ${ }^{78}$ e la cappella di Sant'Elena ${ }^{79}$.

73 G.P. BROGIOLO, Dalla corte regia al monastero di San Salvatore: le sequenze di scavo, in G.P. Brogiolo (a cura di), Dalla corte regia al monastero, op. cit. (n. 15), p. 475-482, come pure M. IBSEN, “Magno et optimo tesauro", op. cit. (n. 1), p. $237-240$.

${ }^{74}$ F. STROPPA, La basilica di San Salvatore: i cicli pittorici altomedievali, op. cit. (n. 2).

${ }^{75}$ F. STROPPA, La basilica di San Salvatore: i cicli pittorici altomedievali, op. cit. (n. 2). Si veda inoltre l'ultimo saggio di F. DE RUBEIS, La tomba della regina Ansa e la sua epigrafe. Ipotesi per una ricostruzione, in M. Jurković, A. Chavarria (eds.), Alla ricerca di un passato complesso. Contributi in onore di Gian Pietro Brogiolo per il suo settantesimo compleanno, Zagreb, 2016 (Dissertationes et monographiae, 8), p. 137-142.

${ }^{76} \mathrm{~F}$. STROPPA, Collezioni longobarde e identità religiosa. Percorsi museali, oggetti liturgici e restauri a Brescia tra Otto e Novecento, in Brixia sacra. Memorie storiche della diocesi di Brescia, ser. $3^{\mathrm{a}}$, XXI, 1-4 (2016), p. 23-90, in part. p. 68-90.

77 G. ARCHETTI, Per la storia di S. Giulia nel medioevo, op. cit. (n. 1), p. 14, 22-28; ID., Vita e ambienti del monastero, op. cit. (n. 1), p. 109-131, in part. 116-117, passim; come pure Rituale, f. $29 r$.

${ }^{78}$ G. ARCHETTI, Per la storia di S. Giulia nel medioevo, op. cit. (n. 1), p. 14, 22-28, in part. p. 25; ID., Vita e ambienti del monastero, op. cit. (n. 1), p. 109-131, in part. 116-117, 125, passim; come pure F. STROPPA, La basilica di San Salvatore: i cicli pittorici altomedievali, op. cit. (n. 2).

79 G. ARCHETTI, Per la storia di S. Giulia nel medioevo, op. cit. (n. 1), p. 25-26; ID., Vita e ambienti del monastero, op. cit. (n. 1), p. 123-124. 


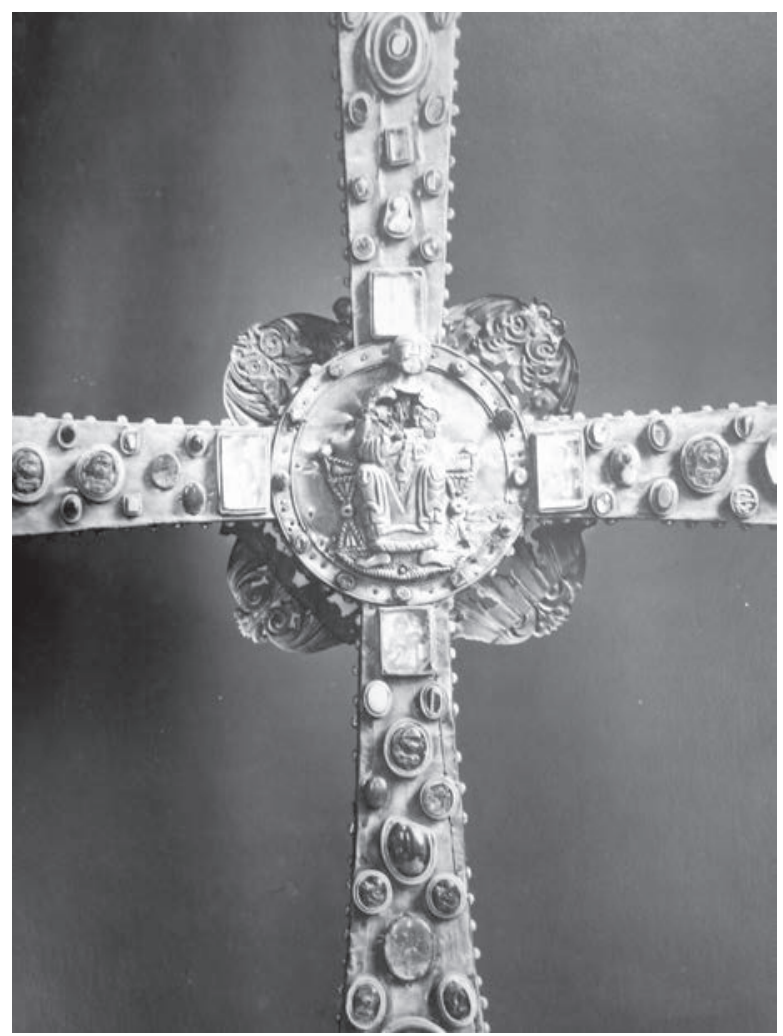

Fig. 9. Brescia, croce di Desiderio, verso, con petali.

Lo strumento di uso processionale, sottoposto dal medioevo fino al Novecento a continui adattamenti, è costituito da un'anima lignea rivestita di lamine metalliche nelle quali sono incastonate numerosissime gemme, tra cammei, pietre dure e paste vitree di differenti cronologie dall'età romana all'inizio del XIX secolo. Su entrambi i lati sono evidenti interventi e sostituzioni: nel verso, all'incrocio dei bracci patenti, si trova il Cristo in trono (fine X-inizio XI secolo) circondato da quattro miniature, due, databili alla fine del X secolo, rappresentano gli evangelisti Marco e Luca e due, raffiguranti Gesù e la Vergine, realizzate a inizio XVI secolo, sono in sostituzione dei pezzi con Giovanni e Matteo, contemporanei alle precedenti miniature e ormai perduti. Al centro della croce, nel recto, è stato collocato il disco fregiato dal Cristo crocifisso di inizio XVI secolo ${ }^{80}$.

La conservazione della memoria della figura di Desiderio non è solo tramandata negli oggetti, ma anche negli scritti: infatti l'indicazione e la denominazione della croce al re longobardo èattestata già negli Annali historici della badessa Baitelli $^{81}{ }^{1657)}$, che recupera la tradizione delle cronache precedenti fondendo varie notizie in una descrizione omogenea con le memorie monastiche, il catalogo delle reliquie, l'elenco delle badesse, i privilegi dei pontefici, le vicende dei fondatori e della martire Giulia. In questa ricchissima raccolta di informazioni, derivanti dalla tradizione scritta e orale, è rivelatrice non solo la descrizione della croce di Desiderio rispetto agli altri preziosi - segno dell'importanza che lo strumento liturgico assumeva per il cenobio - ma anche l'attenzione per il dettaglio del vetro dorato della croce, di origine orientale, che viene letto quale ritratto della famiglia regia longobarda con valenza trinitaria.

La complessità della realizzazione dell'opera, che ha creato problemi attributivi alla storiografia e la cui datazione oscilla in un lasso di tempo molto ampio (tra VII eXI secolo), scaturisce dalle continue manomissioni che hanno portato alla perdita e alla sostituzione di numerose gemme - come pure delle quattro foglie d'acanto laterali (fig. 9) - che, inevitabilmente, hanno falsato l'aspetto originario di fine $\mathrm{X}$-inizio XI secolo, periodo in cui il cenobio affronta importanti trasformazioni, arricchendosi di un potente apparato liturgico-devozionale, preziose decorazioni e ricchi oggetti ornamentali. La datazione tra fine X e inizio XI secolo è sostenuta inoltre dalla riorganizzazione dell'apparato decorativo di San Salvatore e dai collegamenti che, in tarda età ottoniana, il cenobio aveva con l'impero e i monasteri transalpini, come pure dalle relazioni con Bisanzio, suffragati dalla presenza delle Alsengemmen sulla croce ${ }^{82}$, ossia quelle rare produzioni artigianali nordeuropee della fine del X secolo, e dal vetro dorato di gusto orientale e dall'uso dei cammei, che la pongono in parallelo con numerose oreficerie ottoniane ${ }^{8_{3}}$.

\section{TESORO DELLE SANTE CROCI: RETAGGIO GIULIANO}

Il cenobio giuliano non è estraneo al contesto cittadino e, sebbene la storiografia non si soffermi molto su questo aspetto, stretti rapporti intercorrono tra il monastero, seppur autonomo, e l'episcopio con le sue fondazioni cenobitiche, come quelle di San Faustino Maggiore o di Santa Eufemia della fonte. Rimangono alcune tracce dell'interdipendenza tra i due poli religiosi che testimoniano l'influenza del monastero regio che, nel tessuto della città, veicola la diffusione di echi orientali, incentiva la devozione verso la Santa Croce e stimola l'uso strumentale di costruzioni retoriche per celebrare le origini delle istituzioni.

Spie di questo lontanissimo passato si individuano in alcuni aspetti agiografici, devozionali e liturgici che si sviluppano a partire dalla fine del X-inizio XI secolo quale conseguenza di quanto accaduto a cavallo del Mille nel cenobio giuliano. In particolare, in San Faustino Maggiore e nel duomo Vecchio si assiste all'introduzione della devozione verso la Croce con la realizzazione di un sontuoso tesoro, ricco di oggetti di oreficeria, e alla progettazione di una cappella. A ciò segue la costruzione di un racconto mitizzato sulla reliquia della Croce e delle custodie, con conversioni miracolose di personaggi dei poemi epici, legati al potere imperiale e ai vessilli cruciferi; si aggiunge l'arrivo di elementi dai caratteri bizantini come la prima custodia della Santa Croce, il panno sericeo attorno al quale erano stati avvolti i resti di Faustino in Sant'Afra e l'inserimento di nuove dedicazioni, legate a culti orientali, come nel caso del monastero di Sant'Eufemia, fondato da Landolfo II. Forme di biunivoca corrispondenza si attestano anche nel rafforzamento del nesso tra la croce e i patroni della città,

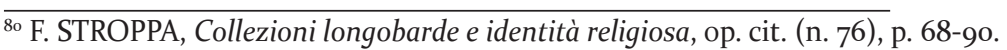

${ }^{81}$ A. BAITELLI, Annali historici, op. cit. (n. 35), p. 14.

${ }^{82}$ E. GAGETTI, Sei Alsengemmen a Brescia, in Pallas. Revue d'études antiques, 83 (2010), p. 55-98 (con bibliografia precedente); inoltre F. STROPPA, Collezioni longobarde e identità religiosa, op. cit. (n. 76).

${ }_{3}^{3}$ F. STROPPA, Collezioni longobarde e identità religiosa, op. cit. (n. 76), p. 68-9o.

${ }^{84} \mathrm{Cfr}$. F. SAVIO, Le lègende des SS. Faustin et Jovite, in Analecta Bollandiana, XV, Bruxelles, 1896; F. STROPPA, L’immagine della martire Giulia nel complesso monastico, op. cit. (n. 3), p. 278.
} 


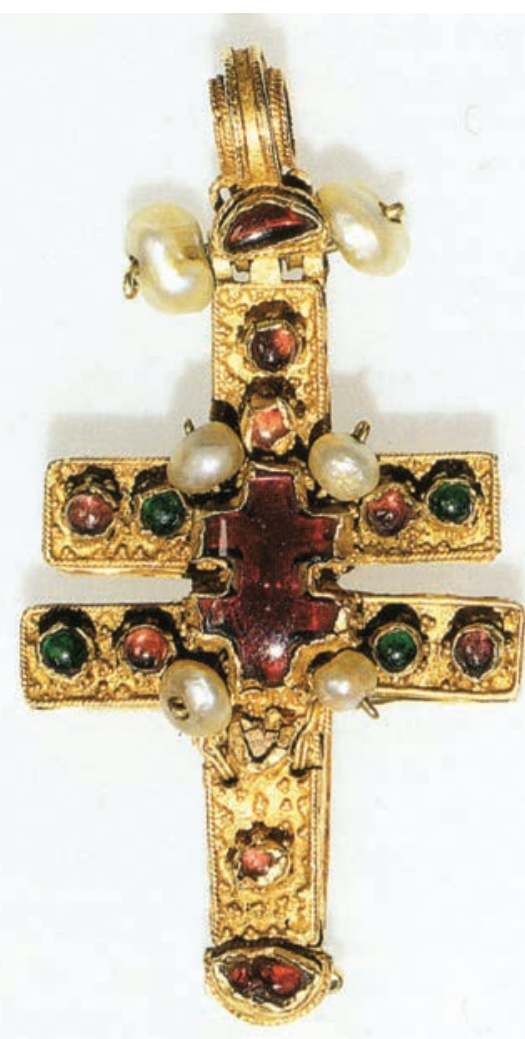

Fig. 10. Brescia, Santa Maria in Solario, croce di Sant'Elena (foto Studio Rapuzzi).

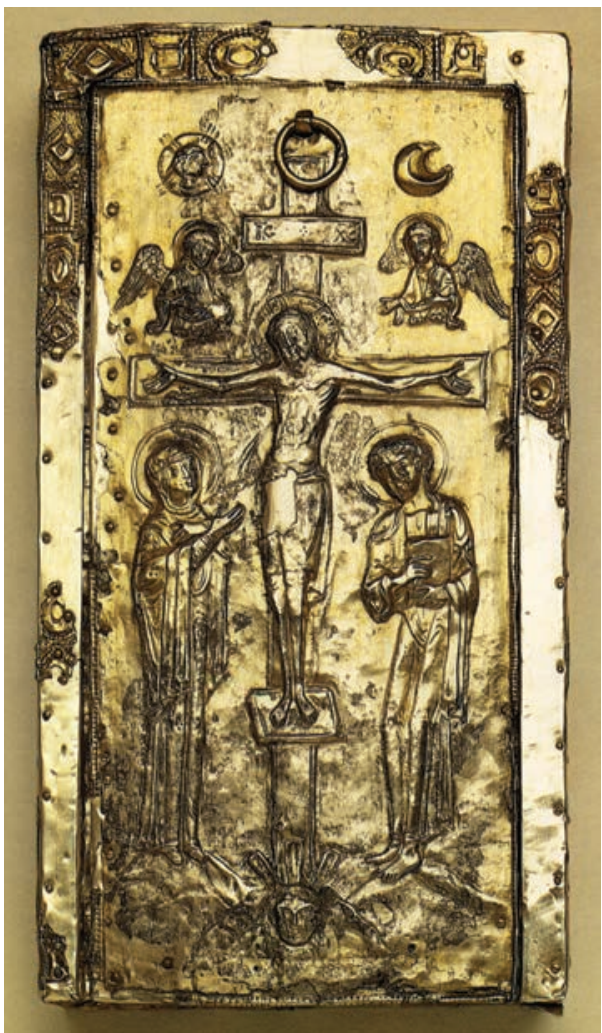

Fig. 11. Brescia, duomo Vecchio, Tesoro delle Sante Croci, stauroteca, coperchio con crocifissione (foto Studio Rapuzzi).

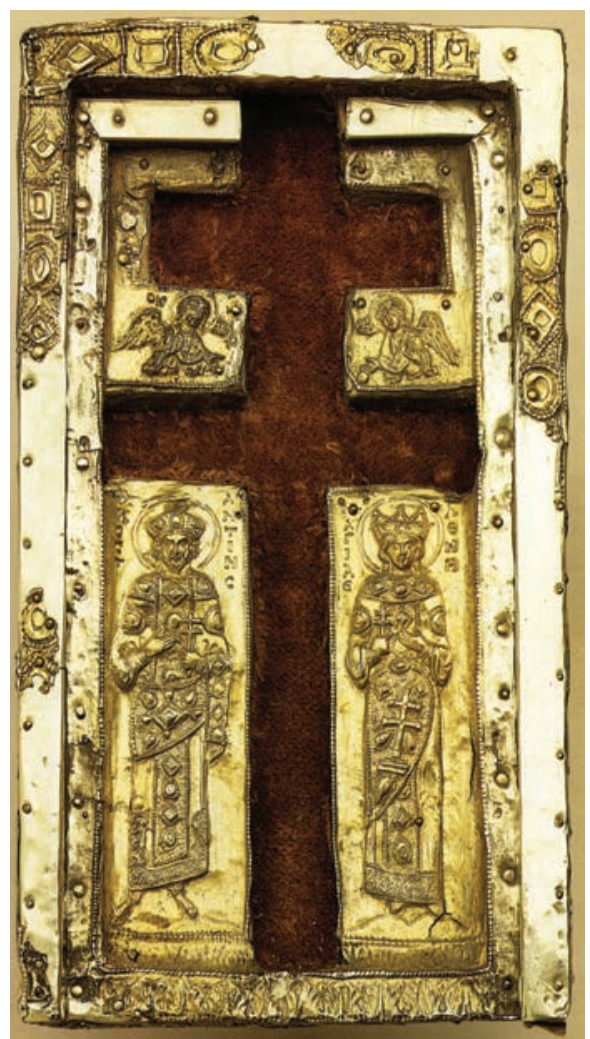

Fig. 12. Brescia, duomo Vecchio, Tesoro delle Sante Croci, stauroteca, interno con Costantino ed Elena (foto Studio Rapuzzi).
Faustino e Giovita ${ }^{84}$, la cui seconda vita stesa nel IX secolo viene presa a modello per la versione occidentale della passio di Elpis, Pistis, Agape e Sophia.

Si rintracciano inoltre elementi che testimoniano le correlazioni nell'inserimento di due reliquiari giuliani, contenenti la sacra spina e la sacra croce, nel tesoro episcopale dopo la soppressione del monastero, forse confluiti nel tesoro del Duomo per celebrare il ricordo del legame tra i due centri e la testimonianza, almeno dal XVII secolo, del nesso tra cenobio ed episcopio indicato dalla badessa Baitelli nell'illustrazione di uno dei più preziosi reliquiari monastici, un encolpio contenente frammenti della croce - denominato Croce di sant'Elena (fig. 10) - che tramanda nelle forme la croce bizantina e viene paragonata alla Croce dell'orifiamma ${ }^{85}$. Da ultimo una reminiscenza, seppur flebile, si individua nella cronachistica locale delle Istorie della città di Brescia ${ }^{86}$ di Elia Cavriolo (1505) nel cui testo, su modello del Chronicon di Malvezzi, si racconta delle vicende bresciane soffermandosi sul monastero che raccoglieva le gloriose spoglie di Giulia - e la «croce del Salvatore nostro Gesù Cristo, del Sepolcro e della Veste sua» - e una ricca dote di croci. La descrizione continua con la fine di re Desiderio, da parte di Carlo e dei suoi prodi, e prosegue con il parallelo tra i paladini dell'impero e i santi patroni, con la reliquia della croce e l'emblema dell'orifiamma cittadina, posta a protezione dei bresciani dalle carestie e dalle guerre fino all'arrivo di Ottone I, descritto come simbolo di pace.

Il Tesoro delle Sante $\mathrm{Croci}^{87}$ è costituito dalla reliquia della Croce $^{88}$ e da sei reliquiari ${ }^{89}$ uno dei quali, la stauroteca (figg. 11, 12), mostra una fattura orientale, nei cui sportello superiore

${ }^{85}$ A. BAITELLI, Annali historici, op. cit. (n. 35), p. 8: «una crocetta d'oro da collo piena di rubini, fu di Santa Elena, fatta nella forma stessa della Santissima croce d'oro e fiamma piena di legno della Santissima croce».

${ }^{86}$ E. CAVRIOLO, Dell'Istorie della città di Brescia, Brescia, 1744, libro V, p. 73-81 (succesiva traduzione italiana della "Chronica de rebus Brixianorum" di Elia Cavriolo). ${ }^{87}$ Per il caso della cattedrale bresciana si veda il volume Le sante croci: devozione antica dei bresciani, Brescia, 20o1: in particolare i saggi di G. SPINELLI, Il culto della vera Croce nella liturgia e nella spiritualità del primo millennio, ivi, p. 13-28; G. PANAZZA, Il tesoro delle Sante Croci nel duomo Vecchio di Brescia, ivi, p. 85-116; P.V. BEGNI REDONA, L'apporto dell'arte alla devozione delle Sante Croci, ivi, p. 117-142; come pure C. Bertelli, C. Stella (a cura di), M'illumino d'immenso, Catalogo della mostra (Brescia, Musei civici di Santa Giulia, 1 aprile-1 luglio 2001), Milano, 20o1. Per la stauroteca e la croce del Campo dopo i saggi di Panazza [G. PANAZZA, Il tesoro delle SS. Croci nel duomo Vecchio di Brescia, in Commentari dell'Ateneo di Brescia per l'anno 1957, Brescia, 1957, p. 101-131; ID., Il tesoro delle SS. Croci nel duomo Vecchio di Brescia, Brescia, 1977; ID., Il tesoro delle Sante Croci nel duomo Vecchio di Brescia, op. cit. (n. 87), p. 85-116] si vedano F. STROPPA, Scheda 61, Croce del Campo, in A.C. Quintavalle (a cura di), Il Medioevo delle cattedrali. Chiesa e Impero: la lotta delle immagini (secoli XI-XII), Catalogo della mostra (Parma, Salone delle Scuderie in Pilotta, 8 aprile-16 luglio 2006), Milano, 2006, p. 593-598 (bibliografia precedente); EAD., Scheda 62, Stauroteca, in A.C. Quintavalle (a cura di), Il Medioevo delle cattedrali, op. cit. (n. 87), p. 598-603 (bibliografia precedente); inoltre EAD., Il Medioevo delle cattedrali, in Brixia sacra. Memorie storiche della diocesi di Brescia, XI, 2 (2006), p. 491-510, in part. p. 508-510; anche F. TASSO, Scheda XII.13. Stauroteca, in R. Salvarani, L. Castelfranchi (a cura di), Matilde di Canossa. Il papato e l'impero: storia, arte, cultura alle origini del romanico, Catalogo della mostra (Mantova, Casa del Mantegna, 31 agosto 2008-11 gennaio 2009), Milano, 2008, p. 418-419; EAD., Scheda XII.14. Croce astile detta croce del Campo, in R. Salvarani, L. Castelfranchi (a cura di), Matilde di Canossa, op. cit. (n. 87), p. 419-421; e C. MAGGIONI, Il tesoro delle Sante Croci, in R. Cassanelli, P. Piva (a cura di), Lombardia romanica. I grandi cantieri, Milano, 2010, p. 99-101.

${ }^{88}$ G. PANAZZA, Il tesoro delle SS. Croci nel duomo Vecchio di Brescia, in Commentari dell'Ateneo di Brescia per l'anno 1957, op. cit. (n. 87), p. 105-107; ID., Il tesoro delle SS. Croci nel duomo Vecchio di Brescia, op. cit. (n. 87), p. 9-11; ID., Il tesoro delle Sante Croci nel duomo Vecchio di Brescia, op. cit. (n. 87), p. 85-116. ${ }^{89}$ I reliquiari sono sei: la stauroteca, la croce del Campo, il bauletto, il reliquiario di Bernardino delle Croci (1474-1487) e i pezzi provenienti dal monastero di Santa Giulia, quali il reliquiario delle Sante Spine equello della Santa Croce (come ipotizza Panazza, frutto di un riuso di due elementi distinti e successivamente 
è illustrata la crocifissione, mentre all'interno dell'astuccio compaiono Costantino e Elena, ai lati dell'incavo contenente un tempo la reliquia della vera Croce, distinta dalla doppia traversa e dagli estremi decorati con placchette a motivi orientali ${ }^{90}$, databili alla fine del X-inizio XI secolo. La stauroteca conservò la reliquia fino al termine del XV secolo quando venne realizzato un nuovo ostensorio in concomitanza con la costruzione della nuova cappella presbiteriale, affrescata da Floriano Ferramola, che lavorava anche in Santa Giulia.

Le cronache bresciane ricordano che al principio il cofanetto e la vera Croce erano custodite nel monastero di San Faustino e successivamente trasferite nella cattedrale di Santa Maria ${ }^{91}$ dal vescovo Oberto Baldrico ${ }^{92}$. Negli Annales Brixienses si rammenta l'incendio, che nel 1096 distrusse Brescia, scoppiato, secondo il cronista Giacomo Malvezzi, a causa della guerra civile per il controllo dell'episcopato: in questo contesto si colloca il racconto moderno degli scontri per la reliquia della Santa Croce del monastero di San Fau- stino ${ }^{93}$, poi traslata in cattedrale come emblema dell'autorità episcopale. I corpi senza vita delle vittime, come riportava l'epitaffio di Baldrico, furono raccolti dal presule che diede loro degna sepoltura, quali nuovi martiri, acconsentendo che il tesoro della Croce fosse riposto nella Rotonda. In tal modo, per una migliore protezione, fu realizzata una cappella reliquiario a torre, progettata secondo schemi imperiali, che si innalzava all'ingresso del tempio a pianta centrale, nella forma tramandata dal modello gerosolimitano.

Al tempo degli scontri e dello spostamento della reliquia la diocesi era guidata da Oberto che fu presule dal 1086 al 1098 (1099), in precedenza forse monaco di San Faustino, secondo la cronotassi abbaziale. La designazione, da parte di Enrico IV, di Oberto a vescovo di Brescia era espressione della serie di nomine episcopali che dalla tarda età ottoniana aveva portato la cattedra cittadina nel Reichskirchensystem imperiale prima dell'arrivo di Arimanno ${ }^{94}$, il quale mantenne l'architettura della torre in facciata di Santa Maria - eretta

unificati, ossia un basamento e una croce astile): cfr. G. PANAZZA, Il tesoro delle SS. Croci nel duomo Vecchio di Brescia, op. cit. (n. 87), p. 107-119; ID., Il tesoro delle SS. Croci nel duomo Vecchio di Brescia, op. cit. (n. 87), p. 11-25; ID., Il tesoro delle Sante Croci nel duomo Vecchio di Brescia, op. cit. (n. 87), p. 85-116. I due pezzi provenienti da Santa Giulia [si veda anche A. VALENTINI, Le santissime croci di Brescia, illustrate con documenti e tavole, Brescia, 1882, p. 74-84] furono trasferiti in cattedrale, dopo la soppressione napoleonica del monastero giuliano; uno di essi, quello con le Sacre Spine rimase in duomo Vecchio, mentre quello con la Santa Croce venne concesso, a titolo di deposito, alla basilica di San Faustino Maggiore il 17 febbraio 1828 dal vescovo Gabrio Maria Nava [A. VALENTINI, Le santissime croci di Brescia, illustrate con documenti e tavole, op. cit. (n. 87), p. 74; I. PANTEGHINI, Scheda 16,16 bis, 16 , ter, 16 quater, 16 quinques. Reliquiario architettonico detto di Santa Croce, in G. MEZZANOTTE et alii, La chiesa e il monastero benedettino di San Faustino maggiore di Brescia, Brescia, 1999, p. 307-309]. In entrambe le preziose teche compare la figura di santa Giulia. Nel reliquiario delle Sacre Spine Giulia si trova nel piccolo tondo collocato nel basamento, insieme a san Benedetto [G. PANAZZA, Il tesoro delle SS. Croci nel duomo Vecchio di Brescia, op. cit. (n. 87), p. 128, nota 38]: la vergine è ritratta con vesti monacali, la palma del martirio e la croce, secondo il modello del capitello antelamico [F. STROPPA, Santa Giulia di Brescia, op. cit. (n. 3), p. 92-10o, in part. p. 99; EAD., Santa Giulia. Percorsi artistici, op. cit. (n. 3), p. 33-44, in part. p. 43], o secondo l'iconografia presente nella silografia del frontespizio - in cui compare la santa in vesti monacali, nimbata e ritratta con la palma, l'ulivo e il crocifisso - del Discorso nel quale brevemente si tratta delle concessioni, privilegi, essentioni, et de' corpi, e reliquie de santi del monantero di Santa Giulia di Brescia, con il catalogo di tutte le abbatesse che sono state di tempo in tempo, Brescia, Vincenzo Sabbio, 1657, opera di Giovanni Battista Nazari [O. VALETTI, Scheda IX.o3, Giovanni Battista Nazari, Discorso nel quale brevemnte si tratta delle concession, privilegi..., in San Salvatore di Brescia. Materiali per un museo. I, op. cit. (n. 4), p. 188-189]. Oltre all'iconografia, aiutano nell'identificazione della santa le iniziali «S. IU». Giulia viene descritta anche nelle piccole figure entro nicchie, alla sommità del reliquiario, insieme alla Madonna con Bambino, san Gerolamo e un santo vescovo [G. VEZZOLI, Scheda VIII.o6. Reliquiario delle Sante Spine (sec. XV e XVI), op. cit. (n. 4), p. 180-181; ID., Scheda VIII.o7. Reliquiario della Santa Croce, ivi, p. 181-182]. Nel reliquiario della Santa Croce, ora in San Faustino, Giulia viene raffigurata nel basamento, a fianco di san Benedetto (iniziali «S. B.») e di san Vittore o san Vincenzo (iniziali «S. V.»). In questo caso non vi sono iniziali, ma le vesti monacali, la palma e la croce la identificano. Si rintraccia un'altra figura della martire, al centro della croce, in corrispondenza dell'incrocio dei bracci dietro la reliquia della Croce custodita entro un cristallo di rocca. La santa è ritratta come una nobile dama coronata distinta dalla palma e dalla croce: sia Valentini che Panteghini [A. VALENTINI, Le santissime croci di Brescia, illustrate con documenti e tavole, op. cit. (n. 87), p. 77; I. PANTEGHINI, Scheda 16, 16 bis, 16, ter, 16 quater, 16 quinques, op. cit. (n. 87), p. 309] la identificano con sant'Elena, tuttavia il racemo vegetale del martirio porta a riconoscere nella figura femminile la vergine cartaginese, come ben riscontra Vezzoli [ID., Scheda VIII.o7. Reliquiario della Santa Croce, op. cit. (n. 4), p. 181-182]. Una simile differenza di iconografia della santa nello stesso pezzo [cfr. F. STROPPA, Santa Giulia di Brescia, op. cit. (n. 3), p. 127-155, in part. p. 153-155; EAD., Santa Giulia. Percorsi artistici, op. cit. (n. 3), p. 79-107, in part. p. 106-107] aggiunge un'ulteriore prova, oltre a quella dei confronti formali, che il reliquiario sia frutto di un assemblaggio che vede il basamento della seconda metà del XV secolo, mentre la croce superiore, forse astile come indica Panazza, della prima metà del XVI secolo.

9o G. PANAZZA, Il tesoro delle SS. Croci nel duomo Vecchio di Brescia, op. cit. (n. 89), p. 9-11.

${ }^{91}$ Cfr. n. 87-89. Inoltre si tengano presenti gli approfondimenti storico-documentari di G. BRUNATI, Di un'antica stauroteca istoriata che si conserva nella vecchia cattedrale di Brescia, Roma, 1839; A. VALENTINI, Le santissime croci di Brescia, illustrate con documenti e tavole, Brescia, 1882; P. GUERRINI, Il tesoro delle Sante Croci nella storia nell'arte, Brescia, 1924; ID., Memorie costantiniane e il culto della croce, Brescia, 1934 (Monografie di storia bresciana, X). $9_{2}^{2}$ G. ARCHETTI, s.v., Oberto Baldrico, in Dizionario biografico degli italiani, LXXIX, Roma, 2013, p. 48-51.

${ }_{93}$ Cfr. G. MEZZANOTTE et alii, La chiesa e il monastero benedettino di San Faustino, op. cit. (n. 87). Per l'approfondimento storico-documentario si veda inoltre G. Archetti, A. Baronio (a cura di), San Faustino Maggiore di Brescia il monastero della città, Atti della giornata nazionale di studi (Brescia, 11 febbraio 2005), Brescia, 2006 (Brixia sacra. Memorie storiche della diocesi di Brescia, XI.1), in part. G. ARCHETTI, Ildemaro a Brescia e la pedagogia monastica nel commento alla Regola, ivi, p. 113-179; P. TOMEA, "Agni sicut nive candidi". Per un riesame della Passio Faustini et Iovite BHL 2836, ivi, p. 17-28; P.V. BEGNI REDONA, La traslazione delle reliquie dei santi a Brescia: tra iconografia e storia, ivi, p. 487-506; come pure G. ARCHETTI, Varietà di esperienze monastiche episcopali a Brescia tra IX e XI secolo, in P. Galetti (a cura di), "Fondare" tra antichità e medioevo, op. cit. (n. 62), p. 259-275.

${ }_{94}^{4}$ Sull'argomento si veda G. ARCHETTI, "Evangelium nuntiare". Chiese, impegno pastorale e forme di religiosità, in G. Andenna (a cura di), A servizio del Vangelo. Il cammino storico dell'evangelizzazione a Brescia, 1. L'età antica e medievale, Brescia, 2010, p. 211-314, 620-632; ID., "Per lodare Dio di continuo". L'abbazia di San Benedetto di Leno, in A servizio del Vangelo, op. cit. (n. 94), p. 399-433, 646-65o; ID., Fraternità, obbedienza e carità. Il modello cluniacense, op. cit. (n. 61), p. 483-513, 654-659; come pure per la parte storico-artistica F. STROPPA, Il Sant'Andrea a Maderno e la Riforma gregoriana nella diocesi di Brescia, Parma, 2007 (Quaderni di storia dell'arte, 24); EAD., Il vescovo Arimanno e la Riforma nella parte orientale della diocesi di Brescia, Università degli studi di Parma, tutor A.C. Quintavalle, coordinatore A. Calzona, XXI ciclo, anno 2009, t. II; EAD., Memoria della Riforma: Arimanno a Brescia, in A.C. Quintavalle (a cura di), Medioevo: immagine e memoria, Atti dell'XI convegno internazionale di studi (Parma, 23-28 settembre 2008), Milano, 2009, p. 396-407; EAD., Le rotonde, le torri e le reliquie nella diocesi di Brescia, in A.C. Quintavalle (a cura di), Medioevo: le officine, Atti del XII convegno internazionale di studi (Parma, 22-27 settembre 2009), Milano, 2010, p. 411-419; EAD., L'attività dei cluniacensi nella diocesi bresciana: programmazione e identità, in A.C. Quintavalle (a cura di), Medioevo: $i$ committenti, Atti del XIII convegno internazionale di studi (Parma, 21-26 settembre 2010), a cura di A.C. Quintavalle, Milano, 2011, p. 442-452. 
probabilmente sul modello giuliano del X secolo - per affermare il successo della riforma romana in una città dalla lunga tradizione filoimperiale.

Le decorazioni alle estremità della reliquia della croce e la stauroteca, realizzate nei primissimi anni dell'XI secolo, sono alcuni degli elementi orientali - come i panni serici che contenevano le reliquie dei santi patroni a Sant'Afra - poco comprensibili nella compagine bresciana. Non sappiamo come siano giunte in città, ma alla luce di quanto detto si può ipotizzare un loro collegamento col cenobio giuliano, grazie all'arcivescovo milanese Arnolfo e al fratello Landolfo, vescovo di Brescia. In altre parole, potrebbero esprimere una tradizione che, riprendendo il culto di Costantino, ebbe un significativo impulso favorito dagli imperatori macedoni, come Basilio I o Costantino VII il Porfirogenito che, non solo si ritenevano discendenti del sovrano e a lui si ispiravano nella ritualità memoriale, ma coltivavano la nozione di santità imperiale per legittimare il potere. Il Porfirogenito in particolare istituzionalizza nel Liber de cerimoniis aulae byzantina, della metà del $\mathrm{X}$ secolo, la celebrazione annuale della memoria di San Costantino: i riti cultuali trovano riscontro nel cerimoniale di corte relativi alla commemorazione di Costantino il Grande in Santa Sophia, nella chiesa dei Santi Apostoli e nella cappella annessa del palazzo di Bono dove il patriarca si recava in processione con l'imperatore il 21 maggio per rendergli omaggio.

A Bisanzio il culto di Costantino fu rilanciato dalla corte imperiale e, nel momento in cui la croce tornava ad essere simbolo della vittoria imperiale, il ricordo di Costantino ed Elena, e del loro ruolo nella nascita del culto delle croci si ravviva. Le fonti bizantine narrano che nella capitale vi fossero immagini che mettevano in luce lo speciale legame tra Costantino, Elena e la croce, sviluppando un cliché che vedeva le due figure accompagnate da angeli, da croci e dalla parola ágios, come si riscontra nella stauroteca bresciana, in cui i due santi imperatori sono descritti con la croce a doppia traversa, il titolo di santo e vesti sfarzose. In particolare Elena è ritratta con una sciarpa a forma di scudo, adorna di pietre preziose, il Thorakion, di norma indossata dalle imperatrici bizantine e diffusa a Bisanzio tra X e XI secolo, seppur risalente all'età tardoantica.

L'aspetto iconografico rappresenta tuttavia lo stadio finale di un percorso che vede una profonda rielaborazione della figura di Costantino ed Elena ${ }^{95} \mathrm{i}$ quali, col fine di celebrare la croce e di legittimare il potere imperiale, vengono indicati come santi $\mathrm{i}^{96}$, sottolineando nella santità imperiale il nesso diretto tra Cristo e l'imperatore, mediatore presso l'umanità della salvezza, attraverso l'azione del buon gover- no. In concomitanza con questo processo vengono stese le vite di san Costantino che, insieme a Elena, è inserito nel calendario liturgico bizantino il 21 maggio ${ }^{97}$, benché il dies natalis - ossia il giorno della morte - fosse il 22 maggio come ricorda il lezionario prebizantino di Gerusalemme ${ }^{98}$. Il ricordo di Costantino ed Elena nel giorno del 21 maggio non consiste tanto nell'istituzione della loro festa quanto nell'introduzione di un'altra festa relativa alla croce, dopo quella dell'inventio e della esaltazione.

Similitudini e richiami del mondo orientale si percepiscono nel cenobio giuliano in modo particolare nella festività di Giulia che viene ricordata nel martirologio il 22 maggio, giorno della morte di Costantino, e nella costante celebrazione delle feste della Croce nella cappella di Sant'Elena ${ }^{99}$. Significativo, inoltre, è il percorso liturgico durante la festa della dedicazione della chiesa ${ }^{100}$ i cui riti partono dalla cappella della madre dell'imperatore: trovandosi nel punto più ad occidente della chiesa, evidente è che l'altare era funzionale al percorso liturgico perché consentiva di attraversare l'intera basilica, tuttavia l'intitolazione a santa Giulia, che per il monastero diventa emblema della croce e riferimento alla regalità, mostra un nesso con santa Elena molto pregnante, richiamato nel Rituale.

Sulla base di quanto detto la morfologia della stauroteca, insieme all'iconografia, trova confronti formali molto stretti con le oreficerie e gli avori di fine X secolo, legati alla corte imperiale sia bizantina che ottoniana. Si vedano per lo schema compositivo le placche eburnee con Cristo che incorona Romano e Eudocia (metà X secolo), quelle del "gruppo di Niceforo" con la crocefissione di Parigi e di Cleveland (seconda metà X secolo), e quella con Cristo che benedice Ottone II e Theofano (fine X secolo), o il Trittico Borradaile conservato a Londra (seconda metà X secolo); mentre per i volti, la postura e i panneggi dei personaggi si possono rintracciare similitudini con la coperta dell'evangelario di Poussay (manoscritto di fine X, con coperta di inizio XI secolo) ${ }^{101} \mathrm{e}$, per i dettagli decorativi degli sfondi descritti da elementi fitomorfi, con l'altare di Basilea (inizio XI secolo).

Lo sviluppo cultuale e l'attenzione verso Costantino il Grande alla corte del Porfirogenito non solo implicava la regolarizzazione delle procedure di corte, ma anche la storiografia: affida, infatti, a Simeone Logoteta la stesura del Chronicon (metà X secolo) in cui si celebrava la storia da Adamo all'anno 948. In particolare il Metafrasta dedica l'opera a «San Costantino il Grande. Costantino il grande e primo cristianissimo imperatore» $(84,16-18)^{102}$, fissandone la corretta vulgata, e realizza un compendio che riassume la

\footnotetext{
${ }_{95}$ Vite di san Constatino (Bibliotheca Hagiographica Graeca, 363 e 366).

${ }_{96}^{6}$ B. CASEAU, La trasmissione nel rituale costantiniano, in Enciclopedia costantiniana, II, op. cit. (n. 40), p. 333-346.

${ }^{97}$ La più antica testimonianza liturgica costantinopolitana di una festa comune a Costantino e a Elena risale all'VIII secolo, tramandata nel manoscritto ms add. 4489, conservato a Cambridge, contenente testi agiografici utilizzati per le commemorazioni liturgiche delle feste tra il 9 maggio e l'8 giugno; cfr. n. 40, 96, 98 .

${ }^{8}$ A. LUZZI, Note sulla recensione del Sinassario di Costantinopoli patrocinata da Costantino VII Porfirogenito, in Rivista di studi bizantini e neoellenici, 26 (1989), p. 139-186; ID., Il "die festus" di Costantino il grande e di sua madre Elena nei libri liturgici della Chiesa greca, in G. Bonamente, F. Fusco (a cura di), Costantino il grande: dall'Antichità all'Umanesimo, Atti del colloquio sul cristianesimo nel mondo antico (Macerata, 18-30 dicembre 1990), II, Macerata, 1993, p. 585-643; ID., Studi sul Sinassario di Costantinopoli, Roma, 1995 (Testi e studi bizantino-neoellenici, VIII).

${ }^{99}$ Rituale, f. 33 r; f. 38 r; f. $38 v$; cfr. n. 72.

${ }^{100}$ Rituale, f. 24v; cfr. n. 72.

${ }^{101}$ Bysance. L'art byzantin dans les collections publiques françaises, Catalogo della mostra (Paris, Musée du Louvre, 3 novembre 1992-1 ${ }^{\mathrm{er}}$ février 1993), Paris, 1992, p. 232-237, 245-252; M. FLAMINE, Gli avori del «gruppo di Romano». Aspetti e problemi, in Acme, LXIII, II (2010), p. 121-152.

${ }^{102}$ D. LAURITZEN, La figura di Costantino il grande negli storici bizantini tra VII e XV secolo, in Enciclopedia costantiniana, II, op. cit. (n. 40), p. 347-364, in part. p. 353 .
} 


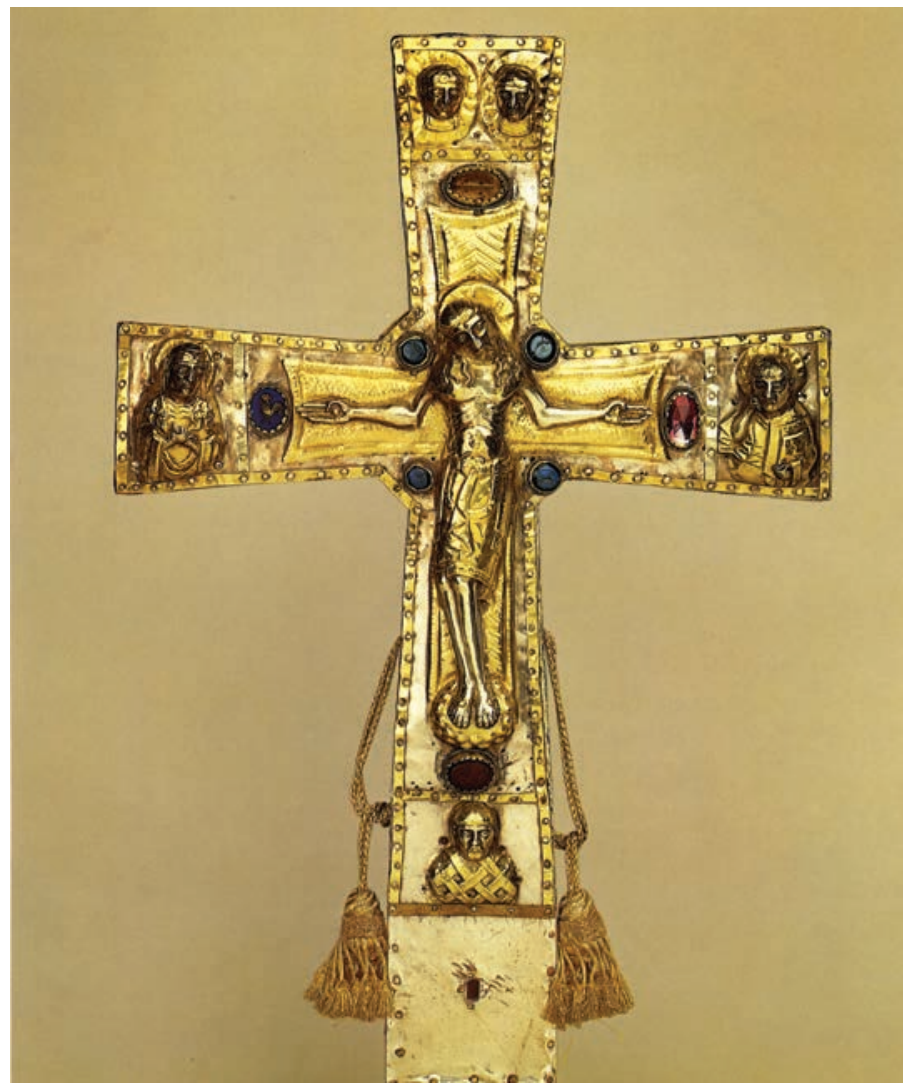

Fig. 13. Brescia, duomo Vecchio, Tesoro delle Sante Croci, croce del Campo (foto Studio Rapuzzi).

vita e il regno di Costantino e che affronta la sua adesione al cristianesimo sotto l'influenza di papa Silvestro ${ }^{103}$. A Simeone Logoteta ${ }^{104}$ viene dato anche il compito di riscrivere alcune vite di santi la cui dedicazione compare a Brescia dall'XI secolo in avanti: in Daniele l'eremita, scelto come santo dedicatario della chiesa dei canonici che accompagnavano la comunità femminile di Santa Giulia, e in Sant'Eufemia della fonte, il cenobio fondato dal vescovo Landolfo II la cui dedicazione orientale non trova altri significativi riscontri in città.

Leggere a questo punto il cenobio giuliano all'interno delle vicende della città, attraverso un percorso sincronico e diacronico, con il monastero di San Faustino ${ }^{105}$ e con la cattedrale cittadina $^{106}$, aiuta a completare l'articolato quadro che vede le vicende di due grandi complessi cenobitici vicini per il culto della croce e per le relazioni intessute con la grande abbazia della Reichenau ${ }^{107}$ in linea con le volontà della dinastia ottoniana.

Con il trasferimento della reliquia della croce da San Faustino al duomo, dopo la guerra civile, si stabilì una tregua che vide alla fine dell'XI secolo l'erezione della torre in facciata, pensata alla stregua di un reliquiario degno e sicuro, conforme ai modelli di Westwerk delle chiese germaniche, in cui la cappella funeraria, dedicata a San Michele, aveva un ruolo fondamentale nei percorsi liturgici. L'operazione venne accompagnata da una costruzione ideologica volta a celebrare, parimenti a santa Giulia, se non maggiormente dato che era la cattedrale cittadina, la reliquia della vera Croce, innalzando la torre (distrutta da un crollo nel 1708), arricchendo il tesoro con la realizzazione della croce del Campo (inizio del XII secolo, fig. 13) e plasmando la leggenda di Namo e dell'orifiamma.

Sullo schema usato nella chanson de Roland della seconda metà dell'XI secolo, in cui si celebra Orlando con i dodici prodi al servizio di Carlo Magno per contrastare i mori e salvare la cristianità, si recupera il nome di uno dei paladini, Namo, facendolo diventare protagonista di un miracolo. Durante la traslazione dei santi Faustino e Giovita da Sant'Afra - dove si trovava il drappo sericeo ${ }^{108}$ - alla basilica di San Faustino, fermandosi per una pausa nei pressi di San Faustino in riposo ${ }^{109}$, Namo vede trasudare sangue dai sacri resti dei patroni e, a seguito dell'evento miracoloso, si converte e dona le reliquie della santa Croce e dell'orifiamma (la croce del Campo) alla città, facendosi monaco nel monastero faustiniano con dodici cavalieri. In tal modo viene ripreso lo schema di Cristo con gli apostoli, attinto nella chanson de Roland, utilizzando Carlo Magno come riferimento imperiale che, a sua volta, aveva donato a Namo, prima di morire la croce e il labarum di tradizione costantiniana, quale simbolo di vittoria sul campo di battaglia, grazie all'intercessione divina della croce emblema della salvezza e del trionfo di Cristo sulla morte.

A proposito della salvezza ultimo indizio, che corrobora quanto detto, è la successiva leggenda del Roverotto - l'apparizione dei due patroni sugli spalti, durante l'assedio del

\footnotetext{
${ }^{103}$ Cfr. n. 102.

${ }^{104}$ Cfr. in generale F. Conca, G. Fiaccadori (a cura di), Bisanzio nell'età dei Macedoni. Forme della produzione letteraria e artistica, Atti della VIII giornata di studi bizantini (Milano, 15-16 marzo 2005), Milano, 2007 (Quaderni di Acme, 87); in particolare si veda A. IACOBINI, Il segno del possesso: committenti destinatari, donatori nei manoscritti bizantini dell'età macedone, ivi, p. 151-194 e L. FRANCO, Le Vite di Simeone Metafrasta: osservazioni sulla tecnica compositiva, ivi, p. 95-118.

${ }^{105}$ Cfr. n. 93.

${ }^{106}$ Per la cattedrale si vedano M. ROSSI, La rotonda di Brescia, apparati archeologici di A. Breda, D. Gallina, rilievi architettonici di R. Marmori, Milano, 2004; P. PIVA, La rotonda di Santa Maria (gruppo cattedrale) di Brescia, in R. Cassanelli, P. Piva (a cura di), Lombardia romanica. I grandi cantieri, op. cit. (n. 87), p. 99-101 (cfr. bibliografia precedente, p. 275); come pure i due testi antichi che rimangono fondamentali per ricostruire le vicende della cattedrale bresciana: B. ZAMBONI, Memorie intorno alle pubbliche fabbriche più insigni della città di Brescia, Brescia, 1778; F. ODORICI, Antichità cristiane a Brescia, illustrate da Federico Odorici in appendice al Museo bresciano, 2. Le sacre edificazioni di Brescia anteriori al secolo XIII, le due cattedrali, monumenti diversi, Brescia, 1858.

${ }^{107}$ G. ARCHETTI, Ildemaro a Brescia e la pedagogia monastica, op. cit. (n. 93), p. 113-179; ID., “Secundum monasticam disciplinam”, op. cit. (n. 1), p. 631-68o. ${ }^{108}$ Il drappo è un tessuto di seta e lana proveniente da San Faustino ad sanguinem, poi Sant'Afra: la decorazione mostra fiere all'interno di una intelaiatura cerchiata simile agli sciamitti presenti nel Mediterraneo o a Bisanzio tra X e XI secolo e che ricorda anche motivi ottoniani, presenti nelle miniature della fine del X secolo sino ai primi decenni dell'XI: dal Codex Egberti (Treviri, Stadtbibliothek, ms 24) all'Evangelario di Ottone III (Monaco, Bayerische Staatsbibliothek, Clm. 4453), realizzato nella abbazia di Reichenau, vicino per confronti formali al coevo codice bresciano, conservato in Queriniana (BQBs, ms F. II. 1) fino ad arrivare al Codex aureus Epternacensis (1030-50, Norimberga, Germanisches Nationalmuseum HS 156142), ff. 38-39, 106-107, 154-155, 222-223. Per la bibliografia sul pezzo bresciano si veda la scheda riassuntiva di Carlo Bertelli: ID., Scheda 428, in G.P. Brogiolo, C. Bertelli (a cura di), Il futuro dei longobardi, Catalogo della mostra (Brescia, Museo di Santa Giulia, 18 maggio-19 novembre 200o), Milano, 200o, p. 449.

${ }^{109}$ Edificio a pianta centrale, vicino alla cattedrale.
} 
1438 da parte delle truppe di Nicolò Piccinino, assoldate dal duca di Milano per riconquistare Brescia da poco entrata nei domini della Repubblica di Venezia - che vede la città difesa dai santi militari, Faustino e Giovita, grazie alla croce e all'orifiamma - segno dell'intervento divino - nel settore nord-est dell'antica cinta muraria corrispondente al cenobio di Santa Giulia: la coincidenza geografica potrebbe sottolineare l'antichissima provenienza del culto urbano delle croci da quello del monastero giuliano.

Da questi presupporti prende avvio la devozione verso la Santa Croce, sulle cui radici la comunità cittadina costruisce le basi per creare il Tesoro del duomo da cui ne trae il nome, verosimilmente giunta in cattedrale con il vescovo Oberto. Le croci riposarono nella torre fino alla realizzazione in presbiterio di una cappella con ulteriori oggetti liturgici il cui nucleo, con la soppressione napoleonica di Santa Giulia, viene arricchito da due reliquiari giuliani: l'operazione suggerisce che fosse ancora viva la tradizione del legame tra il monastero e il culto della croce in città, recuperato solo in un secondo momento dalla cattedrale e dal cenobio maschile di competenza vescovile.

\section{COMMITTENTI E ISPIRATORI}

Gli influssi portati da Santa Giulia a San Faustino, e di seguito al duomo, con la realizzazione del Tesoro delle Sante Croci $^{110}$ sono spia di quanto, durante il X e i primissimi anni dell'XI secolo, maturò nella programmazione teologica e liturgica del cenobio giuliano, espressione come abbazia imperiale di uno straordinario progetto, che intendeva unire la cristianità sotto un unico governo temporale, fondendo oriente e occidente.

Le sparute tracce, a volte poco comprensibili, di fonti storiche, artistiche, liturgiche, agiografiche, devozionali ne tramandano ancora la grandiosità del disegno, concepito nel periodo che si colloca tra Ottone II e Ottone III quando Gerberto d'Aurillac ${ }^{111}$, il futuro papa Silvestro II, era precettore dei due imperatori e dialogava con l'entourage di corte e, in particolare, con Adelaide, nonna di Ottone III, e con la principessa bizantina Theofane, moglie di Ottone II, in una perfetta fusione tra Oriente e Occidente.

La sfaccettata figura di Silvestro II si arricchisce non solo dall'approfondito studio eterogeneo - che spaziava dalla teologia alla letteratura, dalla matematica alla geometria, fino alla musica - ma anche dalle esperienze di viaggio tra la Spagna, Reims, Bobbio, Ravenna e Roma, da cui trae spunto per gli elementi da utilizzare nel racconto. Verosimile è che la sua erudizione abbia tratto ispirazione da dati oggettivi, riprendendo il culto di Giulia - insieme a santa Eulalia ${ }^{112}$ - che aveva già incontrato con l'amico Miro presso Elne ${ }^{113}$ (l'antica Elena), o riecheggiando il mito imperiale di Roma fondata dal troiano Enea che ritrova nella letteratura virgiliana e che utilizza nuovamente nella prefigurazione di Augusto, il divino puer, il cui epiteto ${ }^{114}$ usa per designare Ottone II e Ottone III. Come precettore educa entrambi ad essere il nuovo Costantino regnante su un impero ecumenico fondato sulla nobiltà di stirpe, di animo, di fede e sull'unione dei regni di Oriente e di Occidente per dare avvio ad una nuova era, allo scadere dell'anno Mille.

Infine all'ascesa sul soglio pontificio, la scelta del nome Silvestro II tradisce non solo l'attenzione al suo omonimo predecessore e alla figura di Costantino I, ma anche l'intenzione di proseguire, come successore, l'operazione politico-religiosa impostata nel nome della Croce, il cui culto era alla base delle sue riflessioni nei carmina figurata, sulla scia di Rabano Mauro"15, sui monogrammi relativi al suo nome, simili alle costruzioni del Te igitur, basandosi sull'asse della lettera T, come nel Sacramentario di Drogone ${ }^{116}$.

\footnotetext{
${ }^{\text {"io Cfr. n. } 87 .}$

"m P. RICHÉ, Gerbert d'Aurillac: le Pape de l'an Mil, Paris, 1987; Gerbert, moine, évêque et pape: d'un millénaire à l'autre, Actes des journées d'étude (Aurillac, 9-10 avril 1999), Aurillac 200o; F.G. Nuvolone (a cura di), Gerberto d'Aurillac da abate di Bobbio a papa dell'anno 10oo, Atti del congresso internazionale (Bobbio, 28-30 settembre 200o), Bobbio, 2001 (Archivum Bobiense. Studia, IV); Gerberto d'Aurillac-Silvestro II, linee per una sintesi, Atti del convegno internazionale (Bobbio, 11 settembre 2004), Bobbio, 2005 (Archivum Bobiense. Studio, V); GERBERT D’AURILLAC, Correspondance, Texte établi, traduit et commenté par P. Riché, J.-P. Callu, Paris, 2008; C. Sigismondi (a cura di), Culmina Romulea: fede e scienza in Gerberto, papa filosofo, Atti del convegno (Roma 2007), Città del Vaticano, 2008 (Scienza e fede. Saggi, 8); M. OLDONI, Gerberto e il suo fantasma: tecniche della fantasia e della letteratura nel medioevo, Napoli, 2008; F.G. NUVOLONE, Il numero e la croce: l'homo novus" da Aurillac: prospettive da scritti gerbertiani, Napoli, 2012 (Nuovo medioevo, 87); ID., Da Gerberto a Silvestro II: ermeticità di nome, numeri e Croce nell'anno Mille, Bobbio, 2013.

${ }^{112}$ B. ALART, Les patronnes d'Elne, Paris, 1837, p. 261-277.

${ }^{\text {з }}$ Posta in Francia, nei Pirenei orientali, non lontano dalla Corsica, dove la tradizione racconta che Giulia aveva subito il martirio.

${ }^{144}$ C. Sigismondi (a cura di), Culmina Romulea, passim; p. 99-105; Autour de Gerbert d'Aurillac. Le pape de l'an Mil. Album de documents commentés, Paris, 1996, p. 99-105.

"15 RABANI MAURI In honorem Sanctae Crucis, M. Perrin (ed.), Turnholti, 1997 (Corpus christianorum. Continuatio mediaevalis, 10o).

${ }^{16}$ Paris, Bibliothèque Nationale de France, ms Lat. 9428, c. 15r.
} 